\title{
One for Some or One for All? Taylor Rules and Interregional Heterogeneity
}

\author{
Olivier Coibion \\ College of William and Mary and NBER
}

Daniel Goldstein

The Pennsylvania State University

College of William and Mary

Department of Economics

Working Paper Number 58

Current Version: September 2011

Original Version: September 2007

\footnotetext{
* The authors wish to thank Pok-sang Lam, two anonymous referees, Bob Barsky, Menzie Chinn, Angus Chu, Kathryn Dominguez, Yuriy Gorodnichenko, Chris House, Peter Morrow, Linda Tesar, Matthew Shapiro and seminar participants at the University of Michigan and the College of William and Mary for helpful comments. Olivier Coibion gratefully acknowledges the financial support of the Robert V. Roosa and Jean Monnet Dissertation Fellowships. Daniel Goldstein acknowledges the financial support of the Gerald R. Ford School of Public Policy and the Horace H. Rackham Graduate School.
} 
COLLEGE OF WILLIAM AND MARY

DEPARTMENT OF ECONOMICS

WORKING PAPER \# 58

September 2011

\title{
One for Some or One for All? \\ Taylor Rules and Interregional Heterogeneity
}

\begin{abstract}
We document a novel empirical phenomenon: the U.S. Federal Reserve appears to set interest rates partly in response to regional economic disparities. This result is remarkably robust even after controlling for a wide variety of factors, including the central bank's information set and a battery of explanatory variables. We argue that this finding likely does not reflect an explicit concern about regional differences on the part of policymakers but instead can be explained by a model with non-linear regional Phillips curves. Consistent with the predictions of this model, we find that the Federal Reserve responds disproportionately to fluctuations in low unemployment states. Alternative explanations based on differential effects of monetary policy across regions or regional preferences on the part of voting members of the FOMC cannot account for this finding.
\end{abstract}

JEL Codes: E5, E6

Keywords: Regional Heterogeneity, Monetary Policy, Taylor Rules

Olivier Coibion

Department of Economics

College of William and Mary

Williamsburg, VA 23187-8795

ocoibion@wm.edu
Daniel Goldstein

Department of Economics

The Pennsylvania State University

University Park, PA 16802-3306

Dang@psu.edu 


\section{Introduction}

Are central banks sensitive to variations in economic conditions across regions? The traditional approach to monetary policy research focuses on aggregate measures of economic variables: inflation, output, unemployment, productivity, and other components of these policy models are typically considered across the economy as a whole. As the monetary policy instrument -namely the interest rate chosen by the central bank - applies uniformly across an economy, perhaps the tendency to focus on aggregate measures of economic performance is a natural one. The Federal Reserve Act itself dictates that the FOMC's policies should be made "with regard to their bearing upon the general credit situation of the country" (Federal Reserve Act, section 12Ac, emphasis added), and that the Fed's objective is to support 'the economy's long run potential to increase production, so as to promote effectively the goals of maximum employment, stable prices, and moderate long-term interest rates" (FRA, section 2A).

Despite this, to conclude that interregional variation in economic activity is irrelevant to monetary policy in practice may be premature. Certainly, such variation is in the policy-makers' information set. In the weeks prior to each FOMC meeting, the Federal Reserve Board releases the Beige Book, an informal survey of economic trends in different parts of the country. Furthermore, by mandate, at any time, five of the members of the FOMC represent reserve banks scattered across the nation. That the Federal Reserve Act requires representation from different regions suggests that, at least initially, getting a variety of regional perspectives on the country's economic performance was important. Further evidence on this matter can also be found in transcripts of FOMC meetings themselves. While the brunt of each of these meetings is focused on economic aggregates, at some point in the proceedings the president of each member bank makes a short statement about the status of their region's economy. The FOMC would likely not devote any time to sharing region-specific data if only aggregate information was of importance.

These observations suggest that it is not unreasonable to entertain the notion that interregional variation may play a role in monetary policymaking. For example, if the central bank is facing an aggregate unemployment rate of $5 \%$, does it matter for policymakers if this is driven by half of the country experiencing an unemployment rate of 3\% while the other half faces an unemployment rate of 7\% or does such underlying heterogeneity play no role in decision-making? To investigate this issue, we first turn to the data to see if there is any evidence of central bank sensitivity to such heterogeneity. Our empirical analysis is in the spirit of Taylor (1993), who found that the Federal Reserve's interest rate could be adequately represented via a simple rule in which interest rates change mechanically with various aggregate variables, although we follow the more recent literature which controls for the real-time forecasts of inflation, output growth and unemployment of the Federal Reserve as documented in the 
Greenbooks. ${ }^{1}$ Our baseline tests augment the Taylor rule with measures of regional economic disparities. The empirical results strongly reject the null that the Federal Reserve did not respond to the interregional dispersion of unemployment rates over our time sample of 1983 to 2002: we find that, holding aggregate conditions constant, monetary policy tend to be more contractionary when regional economic disparities are more pronounced. The results hold for various measures of regional dispersion, such as gaps between high and low unemployment regions or the weighted variance of unemployment rates across regions for each period. Similar results hold when we measure interregional dispersion via state-level measures of the output gap or state-specific coincident indices.

This relationship between interest rate decisions and regional economic disparities could arise if macroeconomic shocks have different effects across regions as in Carlino and Defina $(1998,1999)$ or more broadly as a result of the fact that different regions are not perfectly synchronized to the aggregate cycle (Hamilton and Owyang 2009), but the empirical evidence is inconsistent with this interpretation. Our results are robust to controlling for a variety of macroeconomic shocks, leading indicators, the state of the business cycle, or the fact that monetary policy has different effects on different regions. The results should also not be interpreted as reflecting a direct concern about regional disparities on the part of policymakers: we consider a model in which FOMC members dislike regional economic disparities but find no support for the implications of this model in the data. Finally, we rule out another possible channel underlying this result by documenting that there is no evidence that the relationship between interest rate decisions and regional heterogeneity is driven by FOMC members voting based on their regions of origin.

Instead, we argue that the response of policymakers to regional disparities is likely to reflect nonlinearities in the link between prices and labor markets at the regional level. By extending the Barro and Gordon (1983) model to allow for regional nonlinear Phillips Curves, such that low unemployment regions impose greater inflationary pressures than high unemployment regions, we show that even if the central bank cares only about aggregate variables, optimal monetary policy should respond to regional economic disparities in exactly the manner observed in our empirical findings: higher unemployment dispersion for a given aggregate unemployment rate should lead to more contractionary monetary policy because of the non-linearity in the regional Phillips Curves. The mechanism that generates this result is that the central bank needs to react more strongly to fluctuations in low-unemployment states than highunemployment states because the former put more pressure on inflation. Strikingly, we document robust empirical evidence for this mechanism: the Federal Reserve appears to respond more strongly to states with low unemployment rates or high output gaps than to others. Anecdotal evidence from FOMC transcripts also support this channel.

\footnotetext{
${ }^{1}$ See Orphanides (2001 and 2003), Romer and Romer (2004) and Coibion and Gorodnichenko (2011a).
} 
The paper is organized as follows. Section 2 contains the baseline empirical results that suggest that interregional economic disparities matter for policy and numerous attempts to confirm that the result is not a statistical anomaly. Section 3 presents a theoretical interpretation via non-linear regional Phillips Curves, while Section 4 considers other possible explanations. Section 5 summarizes and concludes.

\section{Baseline Results}

This section presents the baseline results of an empirical analysis that examines whether the Federal Reserve responds to interregional heterogeneity. The results indicate that the dispersion of unemployment and output across states is indeed an important predictor of Fed policy.

\subsection{Data and Baseline Results}

Given that interest rates are the primary tool used by central banks in achieving their goals, policymakers' decisions are commonly modeled by an interest rate rule of the type proposed by Taylor (1993)

$$
i_{t}=c+\rho i_{t-1}+\varphi_{\pi} F_{t} \pi_{t+h}+\varphi_{g y} F_{t} g y_{t+h}+\varphi_{u e} F_{t} u e_{t+h}+\varepsilon_{t}
$$

Such a rule relates the interest rate of the central bank $\left(i_{t}\right)$ to its current forecasts (denoted by $F_{t}$ ) of macroeconomic variables at time $t+h$ where $h$ is the forecasting horizon. Following Orphanides (2003) and Ireland (2004), our baseline Taylor rule allows for responses to inflation $(\pi)$ and output growth $(g y)$, as well as a measure of the level of the real economy, for which we use the unemployment rate $(u e){ }^{2}$ Note that the target levels of inflation, output growth and unemployment are assumed to be fixed and are incorporated into the constant term. The lagged interest rate term is included to allow for interestsmoothing on the part of the central bank. The serially uncorrelated error term $\varepsilon_{t}$ represents monetary policy shocks. This specification assumes that interest rates are set in response to current expectations of future values of the independent variables, capturing the well-known fact that monetary policy acts with a lag, forcing policy-makers to be forward-looking. In our baseline specification, we will assume that the relevant time horizon is the next quarter's values for inflation, output growth and unemployment. ${ }^{3}$

To estimate this Taylor rule, we make use of the Greenbook forecasts prepared by the staff of the Federal Reserve Board in anticipation of each meeting of the FOMC. Thus, we can properly account for the real-time forecasts of the Federal Reserve. Following Orphanides (2003) and Coibion and Gorodnichenko (2011a), we estimate the Taylor rule by Ordinary Least Squares. ${ }^{4}$ While Greenbook

\footnotetext{
2 Taylor rules are often specified using the output gap rather than the unemployment rate. We use the unemployment rate because forecasts are available at more flexible horizons in the Greenbooks than the output gap, but we show in section 2.2 that using the output gap makes no qualitative difference to our results.

${ }^{3}$ In section 2.2 , we show that our results are robust to alternative degrees of interest smoothing, alternative forecasting horizons, persistent monetary policy shocks, and nonlinear responses to unemployment.

${ }^{4}$ Coibion and Gorodnichenko (2011a) discuss why OLS is appropriate to estimate the Taylor rule using Greenbook
} 
forecasts are available from 1966 to 2002, we focus on the restricted time period of 1983-2002 because of the time-variation in the Fed's response to macroeconomic variables documented in Clarida, Gali and Gertler (2000) and Boivin (2006). Furthermore, the official policy of targeting non-borrowed reserves between 1979 and 1982 implies that Taylor rules are likely to be a poor description of endogenous monetary policy actions during this time period, as emphasized in Coibion (2010). The FOMC met approximately eight times a year over this time sample, which determines the frequency of our observations.

The first column of Table 1 presents estimates of equation (1). Note that the estimated degree of interest smoothing is high (0.93), as commonly found in the Taylor rule literature. The coefficients are all statistically significant and of the expected sign: the Fed raises interest rates in the face of higher expected inflation and output growth, and lowers interest rates as unemployment rises. Since the long-run response to inflation implied by our point estimates is 2.3 , the Taylor Principle has been satisfied over this time period, again as commonly noted in the Taylor rule literature.

As our interest is in the Fed's possible response to regional disparities in economic conditions, we turn to the construction of these measures. Because of limited availability of high-frequency data at the state level, we focus primarily on the cross-sectional dispersion of unemployment rates. We measure this dispersion in a variety of ways. Our preferred measure is via the population-weighted variance of unemployment rates across states. ${ }^{5}$ Two other measures we employ based on state unemployment rates are the difference between the unemployment rates of the $90^{\text {th }}$ and $10^{\text {th }}$ percentiles of the cross-sectional distribution of regional unemployment rates at time $t$ and similarly for the $80^{\text {th }}$ and $20^{\text {th }}$ percentiles. Note that these measures are available monthly. Figure 1 plots the population-weighted variance of UE rates and these two percentile-based measures. All three measures are highly correlated with one another and experience a pronounced decline over the course of the 1980s and 1990s. All three measures rise substantially after the 1982 and 1990 recessions, whereas no such pattern is apparent for the 2000 recession. The upward-movement in the dispersion measures in the mid-to-late 1980s reflects the drop in oil prices and subsequent economic slowdown concentrated in oil-producing states like Texas, Alaska, Louisiana and Alabama.

In addition, we construct two other measures of regional economic disparities using alternative data sources. The first is based on the state-specific coincident index from the Philadelphia Federal Reserve. The coincident indices combine four state-level indicators to summarize current economic conditions in a single statistic via a dynamic factor model. ${ }^{6}$ The four state-level variables in each

\footnotetext{
forecasts.

${ }^{5}$ We include the District of Columbia as a state in our calculations.

${ }^{6}$ See http://www.philadelphiafed.org/research-and-data/regional-economy/indexes/coincident/ for details. Note that this data excludes the District of Columbia.
} 
coincident index are nonfarm payroll employment, average hours worked in manufacturing, the unemployment rate, and wage and salary disbursements deflated by the consumer price index (U.S. city average). Using data from 1979 to 2006 , we detrend each series individually using a quadratic time trend, yielding a gap measure for each state. We can then construct equivalent monthly measures of regional economic disparities as with the raw unemployment rates: the population-weighted cross-state variance as well as high versus low percentile differentials, which we refer to as coincident gap measures. Secondly, we construct an alternative gap measure for each state using nominal state personal income, which is available quarterly, normalized by each state's population and the aggregate GDP deflator. We then regress the log of each state's real personal income per capita on a constant and quadratic time trend and construct regional dispersions measures, which we refer to as output gap measures, equivalent to those using unemployment rates, albeit at the quarterly frequency.

Figure 2 plots the population-weighted cross-state variances in coincident gaps and output gaps, along with the Federal Funds rate. In addition, Table 1 presents correlations of the three populationweighted variance measures with each other as well as with selected aggregate macroeconomic variables. As could be observed from Figures 1 and 2, the three measures of regional economic disparities are highly correlated with one another. In addition, there is a strong positive unconditional correlation between the interest rate and these dispersion measures over this time period, as well as high correlations with inflation and the aggregate unemployment rate.

To formally assess whether these measures affect central bank decision-making, we augment equation (1) with a measure of regional economic disparities:

$$
i_{t}=c+\rho i_{t-1}+\varphi_{\pi} F_{t} \pi_{t+h}+\varphi_{\Delta y} F_{t} \Delta y_{t+h}+\varphi_{u e} F_{t} u e_{t+h}+\beta D_{t-1}+\varepsilon_{t}
$$

where $D_{t-1}$ is a measure of interregional economic dispersion. We use the lagged value of the dispersion measures to reflect the fact that contemporaneous values were not available to FOMC members at each meeting. Our baseline results are presented in Table 2 for each of our dispersion measures. The results are consistent across specifications and point to a novel empirical finding: greater economic disparities across regions are followed by higher interest rates at FOMC meetings. Each of the point estimates on the regional dispersion measure is significant at the $5 \%$ level or higher. ${ }^{7}$ In addition, while the coefficient estimates differ substantially across specifications, the economic magnitudes are large and broadly similar across measures: the long-run response of interest rates to a permanent one standard-deviation increase in the population-weighted cross-state variances of unemployment rates, coincident gaps and output gaps are estimated to be approximately $3 \%$ points, $1.8 \%$ points and $2.2 \%$ points respectively. Note that these

\footnotetext{
${ }^{7}$ In the interest of space, we do not present equivalent results using percentile-measures for the state coincident or output gaps, but these are qualitatively similar: all point to positive statistically significant responses by the Fed to regional economic disparities.
} 
results do not come at the expense of Fed responses to aggregate macroeconomic variables: the coefficients on the forecasts of future inflation, output growth and unemployment remain significant in all specifications. In the rest of this section, we explore the robustness of our results before turning to potential explanations in subsequent sections.

\subsection{Sensitivity to Specification of the Taylor Rule}

One possible concern with our baseline finding is that it reflects a misspecification of the Taylor rule employed by the Federal Reserve. To address this possibility we consider a variety of alternatives to our baseline. First, we re-estimate equation (2) using alternative forecasting horizons. In Table 3, we present results using a horizon of 2 quarters ahead as well as forecasts for macroeconomic variables in the same quarter as each meeting. Neither change affects the sign or statistical significance of our results for the response to regional economic dispersion, although the coefficient is smaller in the latter case. ${ }^{8}$ Using 2quarter ahead forecasts renders the response to output growth insignificant, which likely reflects the fact that the growth rate of output is very difficult to forecast more than one-quarter ahead, making it a less useful factor upon which to base current monetary policy decisions. Secondly, we allow for a higher order of interest-smoothing. This has no effect on the estimated coefficient on regional dispersion and the coefficients on higher-order interest smoothing are insignificant.

The results in Table 2 indicate that the addition of regional economic disparity measures to the basic Taylor rule significantly increased in absolute value the coefficient on the unemployment forecast. This could indicate that our measures of regional dispersion are picking up some omitted sensitivity of interest rates to the unemployment rate or other measures of the real economy. To see whether this is the case, we consider two tests. First, we replace the unemployment forecast with the Greenbook forecast of the output gap, as in Orphanides (2003) or Coibion and Gorodnichenko (2011a). Column 4 of Table 3 indicates that this does not significantly affect our results. Second, we allow for a non-linearity in the response to unemployment forecasts by including the squared unemployment forecast. The coefficient on this term is small and not statistically significant, while the coefficient on regional dispersion remains positive and highly significant.

Another specification issue concerning Taylor rules is the assumption of non-persistent monetary policy shocks. In our baseline specification, we followed the traditional empirical literature and assumed that the persistence of interest rates reflects interest-smoothing. However, Rudebusch (2006), Carrillo et al (2007), and Consolo and Favero (2009) argue that high degrees of interest-smoothing are unlikely to be an inherent characteristic of monetary policy behavior. Rudebusch (2006) and Carrillo et al (2007) point

\footnotetext{
${ }^{8}$ We also considered a specification with all forecasting horizons from $h=0$ to $h=2$ and this also does not change the significance of the results.
} 
to persistent monetary policy shocks as a more likely cause of interest rate persistence. ${ }^{9}$ To control for this, we re-estimate equation (2) allowing for the errors to follow an $\mathrm{AR}(2)$ process. As illustrated in column 6 of Table 3, this has little effect on the estimated coefficient on regional dispersion.

Each of these specifications uses the lagged value of regional disparities as a regressor, whereas the central bank is assumed to respond to its forecasts of other macroeconomic variables. Unfortunately, no Greenbook forecasts of future regional economic disparities are available, so one cannot comparably assess the possibility that the central bank is responding to expectations of future regional heterogeneity. Instead, we follow Clarida et al. (2000) and estimate (2) using the ex-post values of regional disparities, either 3-months or 6-months after each meeting, by instrumental variables using the one-month lag of regional heterogeneity as the instrument. ${ }^{10}$ As can be seen in columns 7 and 8 of Table 3 , the results are qualitatively unchanged using ex-post values of regional heterogeneity.

Finally, we consider the sensitivity of our results to the time period. First, we break our sample into two sub-periods of equal length of a decade each. Estimating equation (2) over each period, we find few differences, as illustrated in Table 4. The coefficient on regional economic disparities is larger in the second sample although the difference is not statistically significant. In both periods, this coefficient is positive and significant. ${ }^{11}$ Second, we decompose our sample according to the state of the business cycle because Owyang et al. (2005) and Hamilton and Owyang (2009) present evidence that there are asymmetries across states that vary across business cycle phases. In column (4), we present results from estimating equation (2) excluding those FOMC meetings held during recessions. In column (5), we exclude those meetings held during recoveries from recessions, which we define as the 18 months after the end of recessions as defined by the NBER. Neither change in the sample qualitatively affects the estimated coefficient on regional economic disparities, nor does dropping both recessions and recovery periods. If we estimate (2) using only recessions and recoveries, the point estimate on regional heterogeneity is somewhat larger and remains statistically significantly different from zero. Hence, our evidence of a link between interest rate decisions and differences in regional economic conditions is also remarkably robust to the time sample and the state of the business cycle.

\footnotetext{
${ }^{9}$ Coibion and Gorodnichenko (2011b) provide evidence in favor of the interest-smoothing motive over the persistent shocks explanation.

${ }^{10}$ This method relies on the assumption of rational expectations, such that the difference between the ex-ante expectation and the ex-post value is uncorrelated with all information dated $t$ and earlier.

${ }^{11}$ We also estimated equation (2) allowing for time-varying coefficients, as in Boivin (2006) and Coibion and Gorordnichenko (2011). The coefficient on regional economic disparities was consistently positive and exhibited little variation over the time sample. Results available upon request.
} 


\subsection{Controlling for other factors}

While our baseline results are remarkably robust to alternative specifications of the Taylor rule, one might be concerned that some omitted factor is driving this finding. For example, shocks might have differential regional effects, thereby simultaneously leading to changes in regional economic dispersion and to a policy response above and beyond that measured by the Fed's Greenbook forecasts of aggregate macroeconomic variables. Choi and Wen (2010) provide evidence based on a structural VAR that supply and demand shocks led to differential monetary policy responses to the subsequent inflationary and real pressures associated with each type of shock in the post-1979 period. To the extent that macroeconomic shocks affect regions differently, not controlling for them could misleadingly point to a direct response of monetary policy-makers to regional economic disparities. ${ }^{12}$

Our first step is to explicitly control for a variety of macroeconomic shocks directly in the Taylor rule. Specifically, for each shock considered, we estimate

$$
i_{t}=c+\rho i_{t-1}+\varphi_{\pi} F_{t} \pi_{t+h}+\varphi_{\Delta y} F_{t} \Delta y_{t+h}+\varphi_{u e} F_{t} u e_{t+h}+\sum_{j=1}^{4} \gamma_{j} S_{t-j}+\beta D_{t-1}+\varepsilon_{t}
$$

where $S_{t}$ is a shock measure. We use the following shocks from the literature: technology shocks identified as in Gali (1999), news shocks identified as in Beaudry and Portier (2006), uncertainty shocks from Bloom (2009), oil price shocks from Hamilton (1996) and tax shocks from Romer and Romer (2009). ${ }^{13}$ Because most of these shocks are only available at the quarterly frequency, we estimate (3) using the last FOMC meeting of each quarter. By using four lags, we thus control for macroeconomic shocks over the last year before each meeting. The results are presented in Table 5, in which we provide only the estimated coefficients on the lagged shocks and the cross-state population-weighted variance of unemployment rates in the interest of space. In each case, the coefficient on regional dispersion remains positive and highly statistically significant. ${ }^{14}$ Hence, our results cannot be explained via these macroeconomic shocks.

An alternative check for omitted variables is to include leading indicators in the Taylor rule, since the regional economic disparity measures could potentially be correlated with future macroeconomic outcomes not incorporated in the Greenbook forecasts. We do this by estimating equation (3) but

\footnotetext{
${ }^{12}$ Oil price shocks, in particular, would be expected to have very different effects on oil-producing states than on other parts of the country. The large decline of oil prices in 1986, for example, led to substantial increases in unemployment rates in Texas, Alaska, Louisiana and other oil-producing states while the aggregate unemployment rate continued its downward trend.

${ }^{13}$ Details about the shocks are in the Appendix. Note that technology and news shocks are estimated using a VAR with final data. The real-time measures available to policymakers would likely differ somewhat from these measures. The other four shocks are observable in real time.

${ }^{14}$ We also used the log of oil prices rather than Hamilton's oil price shock series because the latter counts only selected positive price changes as shocks, thereby ignoring, for example, the 1986 oil price decline. This yielded very similar results.
} 
replacing lagged macroeconomic shocks with lags of leading indicators. ${ }^{15}$ We consider four such measures: the University of Michigan's Consumer Confidence index, the log of stock prices (DJIA), annual Producer Price Index inflation, and the aggregate coincident index from the Philadelphia Federal Reserve. Panel B of Table 5 presents the coefficient estimates of these indicators and that on the population-weighted cross-state variance of unemployment rates. As with the shock variables, including any of these variables does not materially affect the point estimate on the regional economic disparity measure. Finally, Panel B includes an estimate of equation (2) augmented with a quadratic time trend to control for the similar downward trend in the Federal Funds rate and regional economic disparity measures over this time sample but this also does not affect the coefficient on the cross-state unemployment variance.

In short, it is difficult to wave away our empirical finding on a statistical basis. The result is robust to numerous variations on the baseline specification of the Taylor rule. Similarly, controlling for a variety of other informative variables and measures of historical shocks to the U.S. economy does not eliminate the statistical significance of the estimated coefficient on measures of regional economic disparities. Thus, we turn to possible explanations for this finding.

\section{$3 \quad$ Monetary Policy with Nonlinear Regional Phillips Curves}

To try and account for this empirical regularity, we first present a simple model, in the spirit of Barro and Gordon (1983), which allows for regional nonlinear Phillips Curves and subsequently consider alternative possible theoretical explanations. We follow the Barro and Gordon (1983) framework rather than a fully micro-founded model because the analytical tractability of this framework allows us to consider multiple theoretical explanations within a common theoretical setting. Furthermore, monetary policymakers over most of our time sample were most likely thinking of their objectives and constraints in exactly the context of these models, making them a natural framework for characterizing the basis for their historical decisions.

The literature on nonlinear Phillips Curves goes back to Phillips (1958) himself, who argued that low unemployment rates would lead firms to bid wage rates increasingly higher, thereby generating a non-linear relationship between unemployment rates and prices/wages. Others since have emphasized additional mechanisms which might similarly generate a nonlinear relationship between inflation and slackness of the economy. ${ }^{16}$ Because we do not wish to take a stand on the source of the non-linearity, we

\footnotetext{
${ }^{15}$ We use the lags of leading indicators because current monthly values were not generally observable at the time of each meeting. When we include contemporaneous values in (3), the results are qualitatively unchanged.

${ }^{16}$ Laxton et al (1995) and Alvarez-Lois (2004) present models in which capacity-constraints lead to a nonlinear relationship between inflation and the output gap. Ball et al. (1998) show that higher inflation leads to more frequent
} 
posit the following regional Phillips curve linking regional inflation $\left(\pi_{i}\right)$ to expected inflation $\left(\pi^{e}\right)$ and the regional unemployment rate $\left(u_{i}\right)$ relative to the natural rate $\left(u^{*}\right)$

$$
\pi_{i}-\pi^{e}=-\frac{1}{\alpha}\left(u_{i}-u^{*}\right) u_{i}^{-\beta}+\varepsilon_{a}
$$

such that $0 \leq \beta \leq 1$ where $\beta=0$ yields a standard linear Phillips curve and $\varepsilon_{a}$ is an aggregate shock common to all regions. When $\beta>0$, the Phillips curve is convex, such that lower unemployment rates put increasing upward pressure on inflation. We assume that region-specific inflation rates can be decomposed into an aggregate component $(\pi)$ and a region-specific shock $\left(v_{i}\right)$ such that $\pi_{i}=\pi+v_{i} \cdot{ }^{17}$ Each regional Phillips curve can then be rewritten as

$$
\pi-\pi^{e}=-\frac{1}{\alpha}\left(u_{i}-u^{*}\right) u_{i}^{-\beta}+\varepsilon_{i}
$$

where $\varepsilon_{i} \equiv \varepsilon_{a}-v_{i}$. Thus, the shock to this version of the regional Phillips curve has both aggregate and regional components.

As in Barro and Gordon (1983) and the legal objectives set out in the Federal Reserve Act, the central bank cares only about aggregate measures, as set out in the loss function

$$
L=\frac{1}{2} \pi^{2}+\frac{\lambda}{2}(u-\bar{u})^{2}
$$

where the aggregate unemployment rate is a population-weighted average of regional rates $u=\sum_{i} \omega_{i} u_{i}$ such that $\sum_{i} \omega_{i}=1$ and $\bar{u}$ is the target rate of unemployment. Letting the central bank control inflation directly, the optimal policy under discretion must satisfy

$$
\pi=\alpha \lambda(u-\bar{u}) \sum \omega_{i} \frac{u_{i}^{1+\beta}}{(1-\beta) u_{i}+\beta u^{*}}
$$

Note that when $\beta=0$, i.e. the regional Phillips curves are linear, the last term drops out and the stance of policy depends only on aggregate variables. However, when the Phillips curve is nonlinear such that lower unemployment rates put increasing upward pressure on inflation, then the optimal policy will reflect regional economic differences via the last term on the right-hand side.

To see how changes in regional economic disparities affect the optimal policy, we consider the following experiment. Let the initial distribution of $\varepsilon_{i}$ be non-degenerate such that unemployment rates

updating of prices in menu cost models and therefore to an increased sensitivity of the price level to shocks. Ball and Mankiw (1994) argue that, with positive trend inflation, menu costs lead to more flexible upward-price adjustment than downward-price adjustment and therefore a nonlinear Phillips curve. See Dupasquier and Ricketts (1998) for a more exhaustive overview of potential sources of nonlinearities in the Phillips curve.

${ }^{17}$ There are many reasons why regional inflation rates might differ from the aggregate inflation rate, such as the inclusion of nontradable goods, transportation and distribution costs, etc... We treat the region-specific component as an exogenous shock which need not be uncorrelated across regions and we do not impose that the weighted sum of regional shocks is zero. This is consistent with the construction of the CPI at the national and local levels, for example. In general, one would expect the regional deviations to be persistent, although because we focus exclusively on discretionary policy, this has no effect on the analysis. The presence of regional shocks yields a distribution of unemployment rates across states. Combined with the non-linear regional Phillips curves, this implies aggregate shocks in the model will have different effects across states, a feature emphasized in the regional economics literature. 
are not equal across states when the optimal policy (7) is implemented for a given level of expected inflation. Now consider two states with $\varepsilon_{1}$ and $\varepsilon_{2}$ such that $u_{1}<u<u_{2}$ in the equilibrium. We consider changes to the regional shocks $\left(d \varepsilon_{1}\right.$ and $\left.d \varepsilon_{2}\right)$ which will, in the absence of a policy response, lower the unemployment rate of the low-unemployment state (i.e. $d \varepsilon_{1}<0$ ) and raise the unemployment rate of the high-unemployment state (i.e. $d \varepsilon_{2}>0$ ) while leaving the aggregate unemployment rate unchanged. The latter requires

$$
d \varepsilon_{2}=-\frac{\omega_{1}}{\omega_{2}}\left(\frac{u_{1}}{u_{2}}\right)^{1+\beta}\left[\frac{(1-\beta) u_{2}+\beta u^{*}}{(1-\beta) u_{1}+\beta u^{*}}\right] d \varepsilon_{1} .
$$

The question is then whether this increase in regional economic dispersion will lead to a contractionary policy response (i.e. $d \pi<0$ ) as found in section 2. A sufficient condition for this to hold is given in the following proposition, with proofs in the Appendix.

Proposition 1: In response to $d \varepsilon_{1}<0<d \varepsilon_{2}$ such that (8) is satisfied given $u_{1}<u<u_{2}$, there exists a $\bar{\beta}$ such that $\forall \beta \in(0, \bar{\beta}), d \pi<0$ if $u>\bar{u}$ and $d \pi=0$ if $\beta=0$.

If the central bank cares only about aggregate outcomes (as assumed in the loss function (6)) and the Phillips curves are linear (i.e. $\beta=0$ ), then the increase in regional dispersion should have no effect on the optimal policy, which is the standard result. However, in the presence of mild convexities in the Phillips curves (i.e. $\beta \in(0, \bar{\beta})$ ), an increase in dispersion will lead to more contractionary policy, as observed in the data, when the aggregate unemployment rate is above the target rate. ${ }^{18}$ The latter is the most relevant case in practice since between 1980 and 2002, the unemployment rate exceeded the CBO estimate of the natural rate of unemployment nearly $70 \%$ of the time and the natural rate of unemployment is an upper bound for the Fed's target unemployment rate. Thus, a belief by the central bank in regional nonlinearities can, in principle, account for both the presence of measures of regional economic disparities in the policy rule as well as the sign of the coefficient on these measures identified in Table 2.

However, the response to regional economic disparities in the model does not occur because the central bank cares about regional economic disparities per se. Rather, the result follows from the nonlinearity in the regional Phillips Curves: equivalent shocks across regions in terms of their effects on aggregate unemployment in the absence of a policy response place different pressures on inflation depending on the slackness of the regional economy. Shocks to low-unemployment states have a

\footnotetext{
${ }^{18}$ The effect can be reversed if nonlinearities are sufficiently large. This reflects the fact that the shock to the highunemployment state in the absence of a policy response leads to a flattening of that region's Phillips curve so that a small increase in the inflation rate leads to a big decrease in that state's unemployment rate. If the non-linearity is large enough, this effect can dominate the effect of low unemployment states, leading to an expansionary policy response to an increase in dispersion. See the Appendix for more detail.
} 
disproportionate effect on inflationary pressure and therefore call for stronger policy responses. This mechanism is formalized in the following result:

$$
\begin{aligned}
& \text { Corollary 1: If } d \varepsilon_{1}>0 \text { and } d \varepsilon_{2}>0 \text { are such that }\left.\frac{d u}{d \varepsilon_{1}}\right|_{d \pi=0}=\left.\frac{d u}{d \varepsilon_{2}}\right|_{d \pi=0} \text { given } u_{1}<u_{2} \text {, then } \\
& \qquad \frac{d \pi}{d \varepsilon_{1}}>\frac{d \pi}{d \varepsilon_{2}} \\
& \text { if } \beta \in(0, \bar{\beta}) \text { and } u>\bar{u} \text {. }
\end{aligned}
$$

The corollary shows that if we consider separately shocks to a low and high unemployment state, such that the effects of the shocks would raise aggregate unemployment by the same amount in the absence of a policy response, then policy-makers will respond more strongly via monetary accommodation to the shock in the low-unemployment state than in the high-unemployment region when aggregate unemployment exceeds the target rate.

Since this model is consistent with our baseline finding, we want to assess whether this underlying mechanism is also consistent with the data: has there been a differential response of monetary policy-makers to regional fluctuations depending on the degree of slackness of the regional economy? We decompose our percentile-based measures of regional dispersion into two components: the deviation of high-unemployment regions from the mean $\left(D_{t}^{\text {high }}\right)$ and the deviation of low-unemployment regions from the mean $\left(D_{t}^{\text {low }}\right)$. We construct equivalent measures using the distribution of coincident index gaps and output gaps. For each, we apply this decomposition to the $90^{\text {th }}-10^{\text {th }}$ percentile differences and the $80^{\text {th }}-20^{\text {th }}$ percentile differences. We then estimate the following augmented Taylor rule

$$
i_{t}=c+\rho i_{t-1}+\varphi_{\pi} F_{t} \pi_{t+h}+\varphi_{\Delta y} F_{t} \Delta y_{t+h}+\varphi_{u e} F_{t} u e_{t+h}+\beta_{\text {low }} D_{t-1}^{\text {low }}+\beta_{\text {high }} D_{\mathrm{t}-1}^{\text {high }}+\varepsilon_{t}
$$

Under non-linear regional Phillips curves of the type considered in the model, the theory predicts that $\beta_{\text {low }}<\beta_{\text {high }}$ when using unemployment rates since we would expect higher unemployment originating in low unemployment states to lead to a stronger response (lower interest rates) than when coming from high unemployment states. When using the two gap measures, we would expect the reverse: the central bank should respond more strongly to states with high output gaps than states with low output gaps if high output gap regions are perceived as having a disproportionate effect on inflation.

Table 6 presents the results which are uniformly consistent with the theoretical predictions of the model. Using the unemployment measures, we find evidence that the Fed responds disproportionately to fluctuations in low unemployment states and can reject the null of an equal response to low and high unemployment states. With the coincident index gap and output gap measures, the results point to the Fed responding disproportionately to high gap states and again we can reject the null of equality of 
response to low and high gap states. Across specifications, the signs are also in the expected direction: lower unemployment for low unemployment states leads to higher interest rates while higher output gaps in high output gap states lead to higher interest rates. Thus, despite the different ways in which we measure the degree of slackness at the regional level, the results unambiguously conform to the theoretical predictions of the model. This suggests that the source of the baseline results in section 2 lies not in the Fed caring explicitly about regional disparities but rather could reflect a concern about inflationary pressures accumulating in tight regional labor markets.

The empirical evidence on whether Phillips curves are actually nonlinear, as assumed in the model, is mixed. ${ }^{19}$ However, Laxton, Rose and Tambakis (1999) argue that monetary policy-makers should operate under the assumption that the Phillips curve is non-linear, even in the absence of conclusive evidence for this hypothesis. The reason is that assuming that the Phillips curve is linear when it is actually convex will lead to policy errors that are significantly more costly than those associated with assuming the Phillips curve is non-linear when it is not. This view is consistent with Greenspan's stated policy of risk-minimization in which policy-makers should try to avoid those scenarios that can lead to particularly negative outcomes, which in this case would be a rapid buildup of inflationary pressures arising from increasingly tight regional labor markets or capacity constraints.

Transcripts and minutes from the FOMC meetings are not inconsistent with this interpretation. For example, the minutes of the March 22, 1994 meeting of the FOMC provide the following summary

"In the discussion of the outlook for prices and wages, many members expressed concerns about the potential for a pickup in inflation if, as they anticipated, margins of unemployed resources narrowed further or disappeared. The members acknowledged that broad measures of prices relating to final purchases and of wages currently did not suggest any increase in inflation... To date, the pickup in price increases had been uneven and had tended to be concentrated in some regions or industries in the early stages of the production process, and a number of members reported that they saw little change in inflation trends in their areas. Nonetheless, warning signs had emerged of the prospect of greater inflation, though perhaps not over the nearer term. These included increases in a wide range of commodity prices and anecdotal reports from various parts of the country suggesting a further rise in the number of business firms that were facing somewhat higher prices of materials and other purchases and in turn were able, often for the first time in years, to raise their selling prices. Price and wage pressures appeared to

\footnotetext{
${ }^{19}$ Laxton et al (1995), Turner (1995), and Clark et al (2001) find evidence consistent with a non-linear Phillips curve for the U.S. while Gordon (1997) concludes that the U.S. Phillips curve is linear.
} 
be especially pronounced in the construction industry, where capacity constraints had been encountered in many localities."

These minutes highlight how FOMC members scrutinize local markets for evidence of labor scarcity and capacity constraints in anticipation of subsequent inflationary pressures even when no such pressures are yet apparent in the aggregate data, consistent with the regional Phillips curves assumed in the model. This emphasis on local labor markets and capacity constraints, as illustrated in the model, can lead policymakers to respond to regional heterogeneity even when regional considerations are not part of the central bank's objective function.

\section{Other Theoretical Explanations}

In this section, we consider other possible explanations for our baseline empirical finding that policymakers respond to regional economic disparities. First, we raise the possibility that policy-makers wish to minimize the aggregate loss function but do so while trying to avoid imposing disproportionate losses on any given region, i.e. policymakers are explicitly concerned about regional economic disparities. Second, we address a finding of the regional economics literature that monetary policy shocks have different effects across regions, which could lead policy-makers to focus more on specific regions than others. Third, we allow for regional preferences in voting decisions on the part of FOMC members.

\subsection{Central Bank Preference for Homogeneity}

We first consider the possibility that the central bank cares about regional economic disparities. Specifically, we alter the objective function of the policy-maker to include dual goals: maximize aggregate welfare expressed via aggregate macroeconomic variables while at the same time trying to avoid imposing disproportionate losses on any given region. The goal is to identify how the central bank should respond to regional economic disparities if it did place some weight on minimizing regional differences in welfare.

First, define each region's loss from local unemployment and inflation as

$$
L_{i}=\frac{1}{2} \pi_{i}^{2}+\frac{\lambda}{2}\left(u_{i}-\bar{u}\right)^{2}
$$

with each region's Phillips curve still given by (3) but imposing $\beta=0$ so that each Phillips curve is linear. The link between regional inflation and aggregate inflation remains as in section 3 . We model the central bank's desire to avoid imposing disproportionate losses via the following aggregate loss function:

$$
L=\sum_{i} \omega_{i} L_{i}+\frac{\kappa}{2} \sum_{i} \omega_{i}\left(L_{i}-\sum_{j} \omega_{j} L_{j}\right)^{2} .
$$


When $\kappa=0$, the aggregate loss function is simply a weighted average of regional loss functions and the optimal policy will be equivalent to that of a policymaker whose loss function is defined over aggregate variables (as in (6)). ${ }^{20}$ When $\kappa>0$, the central bank faces an additional penalty which depends on the weighted sum across regions of the difference between each region's loss and the average loss. Thus, the policy-maker cares about aggregate outcomes but also seeks to avoid imposing disproportionate losses on any region. $^{21}$

Defining the optimal policy when $\kappa=0$ as $\pi^{o p t} \equiv \frac{\alpha \lambda}{1+\alpha^{2} \lambda}\left(u^{*}-\bar{u}+\alpha \pi^{e}+\alpha \varepsilon_{a}\right)+v_{a}$ where $v_{a} \equiv \sum_{i} \omega_{i} v_{i}$, we get the following description of optimal monetary policy in the case where $\kappa \geq 0$ :

Proposition 2: The optimal policy $\pi$ that minimizes (11) subject to the regional Phillips curves (3) when $\beta=0$ is

$$
\pi=\pi^{o p t}+\frac{\kappa\left(1+\alpha^{2} \lambda\right) \operatorname{skew}\left(u_{i}\right)}{2 \alpha^{3}\left(1+\frac{\kappa}{\alpha^{2}} \operatorname{var}\left(u_{i}\right)\right)}
$$

where skew $\left(u_{i}\right) \equiv \sum_{i} \omega_{i}\left(u_{i}-u\right)^{3}$ and $\operatorname{var}\left(u_{i}\right) \equiv \sum_{i} \omega_{i}\left(u_{i}-u\right)^{2}$ are both invariant to policy decisions.

Thus, allowing for this additional motive on the part of policy-makers has two important implications for monetary policy. First, policy-makers should respond to the population-weighted skew of unemployment rates, which captures the asymmetry of the distribution. ${ }^{22}$ When it is positive, there is a fat tail of high unemployment rates, whereas when it is negative there is a fat tail of low unemployment states. An increase in the skew, holding all else constant, should be met with more monetary accommodation (i.e. the optimal inflation target is increasing in the skew) as it implies that there are some states with much higher rates of unemployment than others and these will suffer disproportionate welfare losses in the absence of monetary accommodation. Second, the optimal policy should also be a function of the population-weighted cross-state variance of unemployment rates, as found empirically in section 2 . The way in which changes in the cross-sectional variance affect optimal policy depends on the sign of the

\footnotetext{
${ }^{20}$ The only difference between minimizing over (6) and (11) when $\kappa=0$ comes from the fact that $\sum_{i} \omega_{i} v_{i}$ need not be equal to zero, thereby potentially driving a wedge between the optimal inflation rates of each case.

${ }^{21}$ Dixit (2000) and Fuchs and Lippi (2006) consider a similar motivation in the context of models of monetary unions in which the central bank wants to ensure that no country finds it optimal to exit the union. This approach also leads to sensitivity of policy-makers to regional considerations when the participation constraint of a country is binding. Because U.S. states do not have the option of exiting the Federal Reserve system, we are not concerned with participation constraints in this model.

${ }^{22}$ We define the skew in both the theory and the empirics as the weighted sum of cubed differences between state values and the average. The skew is more commonly defined as this weighted sum normalized by the crosssectional standard deviation, but because the theory is expressed in terms of the un-normalized skew, we apply the same definition to the data.
} 
skew of the distribution. If the skew of unemployment rates is positive (as it was in the U.S. on average between 1982 and 2002), an increase in the variance will ceteris paribus reduce the relative importance of high unemployment regions, leading to more contractionary policy as found empirically in section 2 .

To test the predictions of this theory, we estimate an augmented version of equation (2) which includes both the population-weighted cross-state variance of unemployment rates or output gaps, the population-weighted skew of unemployment rates or output gaps and an interaction term. The theory predicts that the coefficient on the skew of unemployment rates should be negative (positive if using output gaps) and that on the interaction term should be positive (negative if using output gaps). The results are presented in Table 7. Using either the distribution of unemployment rates or output gaps, we find no evidence that the Fed responded to the skew of the cross-sectional distribution and the coefficients on the interaction terms are insignificant as well. ${ }^{23}$ This lends further credence to the notion that our baseline finding of a relationship between interest rate decisions of the Fed and regional economic disparities is not driven by an explicit concern about regional heterogeneity on the part of policymakers.

\subsection{Differential Regional Effects of Monetary Policy Shocks}

While our baseline empirical finding is that regional economic disparities appear to affect interest rate decisions of monetary policy-makers in the U.S., the converse also appears to be true: monetary policy changes have differential regional affects. Carlino and DeFina (1998) find that monetary policy shocks have a particularly large effect on the Great Lakes region while the Southwest and Rocky Mountain regions are much less sensitive to monetary policy shocks than the average across regions. Carlino and DeFina (1999) show that there are notable differences across states as well. If policymakers take into account these differential effects of policy changes across regions, then this could potentially account for our baseline finding.

To see how this can be the case, consider a central bank which tries to minimize the aggregate loss function (6) subject to regional Phillips curves with different slopes:

$$
\pi=\pi^{e}-\frac{1}{\alpha_{i}}\left(u_{i}-u^{*}\right)+\varepsilon_{i}
$$

where all variables are defined as in equation (5). The only difference relative to (5) is that each regional Phillips curve is linear, but the slope may differ across regions as determined by $\alpha_{i}{ }^{24}$ With aggregate inflation as the policy instrument, a region with a high $\alpha_{i}$ is particularly sensitive to monetary policy while

\footnotetext{
${ }^{23}$ The results using coincident gaps, not presented here, are similar: the coefficient on both the skew and the interaction term are not significantly different from zero.

${ }^{24}$ The slopes of regional Phillips Curves could differ across regions for a variety of reasons such as different industry compositions, state and local tax rates, unionization rates, etc...
} 
one with a low $\alpha_{i}$ is particularly insensitive to monetary policy. This setup yields the following implications for optimal monetary policy and regional disparities:

Proposition 3: If the central bank minimizes loss function (6) subject to regional Phillips curves (12), the optimal policy rule is

$$
\pi=\pi^{o p t}+\left(\frac{\alpha \lambda}{1+\alpha^{2} \lambda}\right) \sum_{i} \omega_{i}\left(1-\frac{\alpha}{\alpha_{i}}\right)\left(u_{i}-u^{*}\right)
$$

where $\alpha \equiv \sum_{i} \omega_{i} \alpha_{i}$ is the slope of the population-weighted aggregate Phillips curve, $\pi^{o p t} \equiv\left(\frac{\alpha \lambda}{1+\alpha^{2} \lambda}\right)\left(u^{*}-\bar{u}+\alpha \pi^{e}+\alpha \widetilde{\varepsilon_{a}}\right)$ is the optimal policy when all regions have the same slope of the Phillips curve given by $\alpha$, and $\widetilde{\varepsilon_{a}} \equiv \varepsilon_{a}-\sum_{i} \omega_{i} v_{i}$.

The proposition shows that the optimal policy depends not just on aggregate variables but also on a measure of regional economic disparities which is invariant to policy decisions. ${ }^{25}$ This measure depends positively on the unemployment gap of states that are more sensitive to monetary policy than average and negatively on the unemployment gap of states that are less sensitive to monetary policy than average.

To assess whether this theoretical mechanism accounts for the interest rate response of the Fed to regional economic disparities, we construct a set of regional unemployment gaps that focus on the regions which have been found to be noticeably more or less sensitive than the average to monetary policy shocks. For example, we construct a measure of the unemployment gap for highly sensitive states by taking a population-weighted average of unemployment rates in these states relative to the aggregate unemployment rate. The gap measure for states that are relatively insensitive to monetary policy is computed in the same way following the results in Carlino and DeFina (1999). We construct analogous measures for regions following Carlino and DeFina (1998). ${ }^{26}$ Table 7 presents the results from estimating equation (2) augmented to include these measures. We find no evidence that interest rate decisions respond to the unemployment gaps for either highly sensitive or insensitive states or regions, and for each specification, the coefficient on regional economic disparities remains statistically significant. Thus, our results do not appear to be driven by the central bank taking into account the fact that monetary policy has differential effects across regions.

\footnotetext{
${ }^{25}$ The invariance to policy decisions reflects the fact that $\sum_{i} \omega_{i}\left(1-\frac{\alpha}{\alpha_{i}}\right)\left(u_{i}-u^{*}\right)=\sum_{i} \omega_{i}\left(\alpha_{i}-\alpha\right) \varepsilon_{i}$ which is a function only of the shocks.

${ }^{26}$ The states most sensitive to monetary policy include Arizona, Indiana, Michigan, New Hampshire and Oregon, while the least sensitive states include Louisiana, Oklahoma, Texas and Wyoming. The region most sensitive to monetary policy is the Great Lakes region while the least sensitive are the Rocky Mountains and Southwest regions. See Carlino and DeFina (1998 and 1999).
} 


\subsection{Regional Voting Shares}

Another avenue through which regional economic disparities could affect interest rate decisions is if voting members of the FOMC place disproportionate weight on the region from which they originate. Meade and Sheets (2005) and Chappell et al. (2008) provide evidence that voting members of the FOMC do, in fact, respond particularly strongly to economic developments in their region of origin when voting on interest rate decisions. If the voting members of the FOMC are not representative of the geographical distribution of the population, this can lead to the central bank having regional weights which differ from their population weights. In fact, the historical record of voting decisions by FOMC members point to a significant misrepresentation of the geographical distribution of the population. For example, the district associated with the New York Fed has accounted for 17\% of the votes at FOMC meetings between 1982 and 2000 while only accounting for $7 \%$ of the U.S. population. At the other extreme, the districts associated with the Atlanta and San Francisco Feds have been the most under-represented in FOMC meetings: their shares of votes have been $3 \%$ and $8 \%$, while their population shares were $14 \%$ and $19 \%$ respectively. Furthermore, because some of the voting rights rotate among members of the FOMC, different regions are over or under-represented at different times. Thus, to the extent that regional differences play a role in voting decisions of individual members of the FOMC, this time-varying bias in the representation of different regions could generate a link between interest rate decisions and regional economic disparities.

To see more precisely how such geographic misrepresentation can affect policy decisions, suppose the central bank seeks to minimize the loss function

$$
L=\sum_{i} \Omega_{i}\left(\frac{1}{2} \pi_{i}^{2}+\frac{\lambda}{2}\left(u_{i}-\bar{u}\right)^{2}\right)
$$

which is a weighted average of regional losses in which the weights associated with each region $\left(\Omega_{i}\right)$ may differ from the population-weight $\left(\omega_{i}\right)$ and $\sum_{i} \Omega_{i}=1$. We assume linear regional Phillips Curves

$$
\pi_{i}=\pi^{e}-\frac{1}{\alpha}\left(u_{i}-u^{*}\right)+\varepsilon_{a}
$$

where, as in section 3, each region's inflation is related to aggregate inflation via $\pi_{i}=\pi+v_{i}$ where the $v_{i}$ 's are regional shocks. Then one can readily show that the optimal policy is given by

$$
\pi=\pi^{o p t}+\frac{1}{\alpha} \sum_{i} \Omega_{i}\left(u_{i}-u\right)
$$

where $\pi^{o p t} \equiv \frac{\alpha \lambda}{1+\alpha^{2} \lambda}\left(u^{*}-\bar{u}+\alpha \pi^{e}+\alpha \varepsilon_{a}\right)-\sum_{i} \omega_{i} v_{i}$ is the optimal policy when $\Omega_{i}=\omega_{i}$ for all $i$. The desired stance of monetary policy therefore depends on aggregate variables as well as a weighted average of regional unemployment gaps, which is generally non-zero when the weights in the loss function differ from the population weights. As a result, regional preferences in voting decisions by FOMC members combined with voting shares that differ from the geographical distribution of the population can potentially account for the sensitivity of interest rate decisions to regional economic disparities observed 
in the data. ${ }^{27}$ For example, rising unemployment in high unemployment states combined with falling unemployment in low unemployment states will lead to more contractionary monetary policy if the voting weights disproportionately represent low unemployment regions.

To assess this hypothesis, we construct a measure of weighted regional unemployment gaps, where the weights are given by the voting representation of each region, as implied by the optimal policy function (17). Using data from Meade and Sheets (2005) between 1983 and 2000, we take the fraction of votes associated with each Fed district on any given meeting of the FOMC and multiply these fractions by the difference between the (one-month lagged) unemployment rates for each district and the (one-month lagged) aggregate unemployment rate. ${ }^{28}$ An equivalent measure is constructed using output gaps for each district. Table 7 presents estimates of an augmented version of equation (2) which includes the population-weighted cross-state variance of either unemployment rates or the output gap and the corresponding measure of dispersion from voting representation. In both cases, the coefficient on the cross-state variance term remains positive and highly significant while the coefficients on the voting share weighted regional dispersion measures are insignificantly different from zero. Thus, regional preferences in voting decisions also cannot account for our baseline finding of interest rate responses to a variety of measures of regional economic disparities.

\section{Conclusion}

We present robust evidence that the interest rate decisions of the U.S. Federal Reserve have been systematically related to heterogeneity in economic conditions across states after controlling for contemporaneous and expected aggregate macroeconomic conditions. This finding could potentially be due to a number of factors. In particular, given the strong unconditional correlation between measures of regional economic disparities and aggregate macroeconomic conditions, the apparent response of interest rates to regional differences could reflect misspecification of the Taylor rule or an omitted variable. While the latter can never be completely ruled out, we show that our results are robust to controlling for a variety of macroeconomic shocks, forward-looking variables, alternative Taylor rule specifications, and sub-sample estimates over different phases of the business cycle. Hence, it is difficult to explain this robust empirical relationship on purely statistical grounds.

\footnotetext{
${ }^{27}$ While we model the effect of regional preferences directly via the weights in the loss function. Aksoy et al. (2002) reach a similar conclusion by explicitly modeling the outcomes under majority voting rules such as that used by the FOMC. Specifically, they find that majority voting rules can lead to suboptimal monetary policy from an aggregate point of view if voting decisions by individual members are affected by regional considerations.

${ }^{28}$ Some states are split between Federal Reserve districts. Appendix 2 describes the precise allocation of states to Fed districts used to construct the gap series.
} 
Instead, we argue that the apparent response of policy-makers to regional economic disparities likely reflects concerns about the possibility of non-linearities in regional Phillips curves, such that lowunemployment regions put disproportionate upward pressure on inflation. In such a setting, optimal policy dictates disproportionately strong responses by monetary policy-makers to low unemployment or high output gap regions, a result which is confirmed in the data. The model used to account for the response of policy decisions to regional disparities, namely the Barro and Gordon (1983) framework augmented with regional non-linear Phillips curves, is likely to be representative of how policymakers viewed their objectives and tradeoffs during the time period of the analysis. As such, it is a useful framework to characterize the best response of policymakers to both aggregate and regional conditions. However, the model -without microfoundations- is ill-suited to address the question of what optimal policy would be from a welfare point of view in the presence of nonlinear regional Phillips curves. Similarly, answering the question of whether this response of policymakers to regional conditions was quantitatively important in affecting macroeconomic conditions requires a more dynamic setting. A key next step in this line of research would therefore be to integrate our setup into a fully dynamic model with microfoundations.

Recent events suggest that this line of research could yield important insights. For example, the U.S. housing price increases of the mid-2000's were concentrated in a subset of states such as California, Florida, and Nevada, all of which had above average output gaps between 2004 and 2006. The model with non-linear regional Phillips curves indicates that such a pattern would call for a greater increase in interest rates than would be warranted from looking only at aggregate variables. Yet anecdotal evidence suggests that, unlike in the past, these regional considerations had little influence on monetary policy decisions at the time (i.e. "froth in some regions"). Assessing whether the sensitivity of monetary policy decisions to regional considerations changed over this time period could help gauge whether interest rates were held lower than they would have been in the past, as has been suggested by some, and what role this policy stance may have played in further fuelling housing price increases in these regions.

Similarly, the recent sovereign debt issues in Greece and other European countries have called into question the extent to which the European Central Bank (ECB) should respond to country or regionspecific shocks in the Euro-Area. Compared to the U.S., the possible motives for region-specific responses by the ECB are likely to be substantially amplified: the variance of regional shocks is almost certainly greater in Europe, the dramatic differences in economic structures across countries likely imply substantial heterogeneity in country-specific responses to monetary policy shocks, and the voting representation in the Governing Council of the ECB is even less representative of the regional distribution 
of the population than the FOMC. ${ }^{29}$ Furthermore, these regional factors will only grow as the Euro-Area expands to include East European countries. Thus, better understanding the implications of regional economic disparities for optimal policy-making is likely to be an important step for future research.

${ }^{29}$ For example, the three biggest countries (France, Germany and Italy) jointly accounted for $65 \%$ of the Euro-area population between 1999 and 2006 but only 32\% of the votes in the ECB Governing Council. 


\section{References}

Aksoy, Yunus, Paul De Grauwe, and Hans Dewachter. 2002. "Do Asymmetries Matter for Monetary Policy?" European Economic Review. Vol. 46: 443-469.

Alvarez-Lois, Pedro P., 2004. "Capacity Constraints, idiosyncratic demand uncertainty and the dynamics of inflation," Economics Letters 83: 15-21.

Ball, Laurence M. and N. Gregory Mankiw, 1994. "Asymmetric Price Adjustment and Economic Fluctuations," Economic Journal 104(423): 247-261.

Ball, Laurence M., N. Gregory Mankiw, and David H. Romer, 1998. "The new Keynesian economics and the output-inflation trade-off," Brookings Papers on Economic Activity 19(1) 1-82.

Barro, Robert J. and David B. Gordon. 1983. "A Positive Theory of Monetary Policy in a Natural Rate Model," Journal of Political Economy. Vol. 91: 589-610.

Beaudry, Paul and Franck Portier, 2006. "News, Stock Prices and Economic Fluctuations," American Economic Review 96(4), 1293-1307.

Bloom, Nicholas, 2009. "The Impact of Uncertainty Shocks," Econometrica 77(3) 623-685.

Boivin, Jean, 2006. "Has U.S. Monetary Policy Changed? Evidence from Drifting Coefficients and Real-Time Data," Journal of Money, Credit and Banking 38(5) 1149-1173.

Carrillo, Julio, Patrick Fève, and Julien Matheron, 2007. "Monetary Policy Inertia or Persistent Shocks: A DSGE Analysis" International Journal of Central Banking 3(2) 1-38.

Carlino, Gerald, and Robert DeFina. 1998. "The Differential Regional Effects of Monetary Policy," Review of Economics and Statistics. Vol. 80: 572-587.

Carlino, Gerald, and Robert DeFina, 1999. "The Differential Regional Effects of Monetary Policy: Evidence from the U.S. States," Journal of Regional Science, 39(2) 339-358.

Chappell, Henry W., Rob R. McGregor, and Todd A. Vermilyea. 2008. "Regional Economic Conditions and Monetary Policy," European Journal of Political Economy, 24(2) 283-293.

Choi, Woon Gyu and Yi Wen, 2010. "Dissecting Taylor Rules in a Structural VAR" Federal Reserve Bank of Saint Louis Working Paper 2010-005.

Clarida, Richard, Jordi Gali, and Mark Gertler. 2000. "Monetary Policy Rules and Macroeconomic Stability: Evidence and Some Theory," Quarterly Journal of Economics. 115(1): 147-180.

Clark, Peter, Douglas Laxton and David Rose, 2001. "An evaluation of alternative monetary policy rules in a model with capacity constraints," Journal of Money, Credit and Banking 33(1) 4264.

Coibion, Olivier and Yuriy Gorodnichenko, 2011a. "Monetary Policy, Trend Inflation and the Great Moderation: An Alternative Interpretation" American Economic Review 101(1) 341-370.

Coibion, Olivier and Yuriy Gorodnichenko, 2011b. "Why Are Target Interest Rate Changes So Persistent?" NBER Working Paper w16707.

Coibion, Olivier, 2010. "Are the effects of monetary policy shocks big or small?" forthcoming in the American Economic Journal: Macroeconomics.

Consolo, Agostino and Carlo A. Favero, 2009. "Monetary policy inertia: More a fiction than a fact?" Journal of Monetary Economics 56(6) 900-906.

Dixit, Avinash. 2000. "A Repeated Game Model of Monetary Union,” The Economic Journal. Vol. 110: 759-780.

Dupasquier, Chantal and Nicholas Ricketts, 1998. "Non-Linearities in the Output-Inflation Relationship: Some Empirical Results for Canada," Bank of Canada Working Paper 98-14.

Fuchs, William and Francesco Lippi. 2006. "Monetary Union with Voluntary Participation," Review of Economic Studies. Vol. 73. 437-457.

Gali, Jordi, 1999. "Technology, Employment, and the Business Cycle: Do Technology Shocks Explain Aggregate Fluctuations?" American Economic Review 89(1), 249-271.

Gordon, Robert J., 1997. "The time-varying NAIRU and its implications for economic policy," Journal of Economic Perspectives 11(1) 11-32. 
Hamilton, James D., 1996. "This is what happened to the oil price-macroeconomy relationship," Journal of Monetary Economics 38, 215-220.

Hamilton, James D. and Michael T. Owyang, 2009. "The Propagation of Regional Recessions," Federal Reserve Bank of St. Louis Working Paper 2009-013A.

Ireland, Peter N., 2004. "Technology Shocks in the New Keynesian Model," Review of Economics and Statistics 86(4) 923-936.

Laxton, Douglas, Guy Meredith and David Rose, 1995. "Asymmetric effects of economic activity on inflation: Evidence and policy implications," IMF Staff Papers 42(2) 344-374.

Laxton, Douglas, David Rose and Demosthenes Tambakis, 1999. "The U.S. Phillips curve: The case for asymmetry," Journal of Economic Dynamics and Control 23(9) 1459-1485.

Meade, Ellen E. and D. Nathan Sheets. 2005. "Regional Influences on FOMC Voting Patterns," Journal of Money, Credit, and Banking. Vol. 37, No. 4: 661-677.

Orphanides, Athanasios. 2001. "Monetary Policy Rules Based on Real-Time Data," American Economic Review, Vol. 91 No. 4. Pp. 964-985.

Orphanides, Athanasios, 2003, "Historical Monetary Policy Analysis and the Taylor Rule," Journal of Monetary Economics, 50(5), 983-1022.

Owyang, Michael T., Jeremy Piger, and Howard J. Wall, 2005. "Business Cycle Phases in U.S. States," Review of Economics and Statistics 87(4), 604-616.

Phillips, Alban W., 1958. "The Relation between Unemployment and the Rate of Change of Money Wage Rates in the United Kingdom, 1861-1957," Economica 25(100) 283-299.

Romer, Christina D. and David H. Romer. 2004. "A New Measure of Monetary Shocks: Derivation and Implications," American Economic Review. Vol. 94 No. 4: 1055-1084.

Romer, Christina and David H. Romer, 2009. "The Macroeconomic Effects of Tax Changes: Estimates Based on a New Measure of Fiscal Shocks," forthcoming in American Economic Review.

Rudebusch, Glenn D., 2006. "Monetary Policy Inertia: Fact or Fiction," International Journal of Central Banking 2(4) 85-135.

Taylor, John B. 1993. Discretion versus Policy Rules in Practice. Carnegie Rochester Conference Series on Public Policy. Vol 39: 195-214.

Turner, Dave, 1995. "Speed Limit and Asymmetric Effects from the Output Gap in the Seven Major Countries," OECD Economic Studies 24.

Woodford, Michael. 2003. Interest and Prices: Foundations of a Theory of Monetary Policy. Princeton: Princeton University Press. 
Figure 1: Regional Unemployment Dispersion Measures

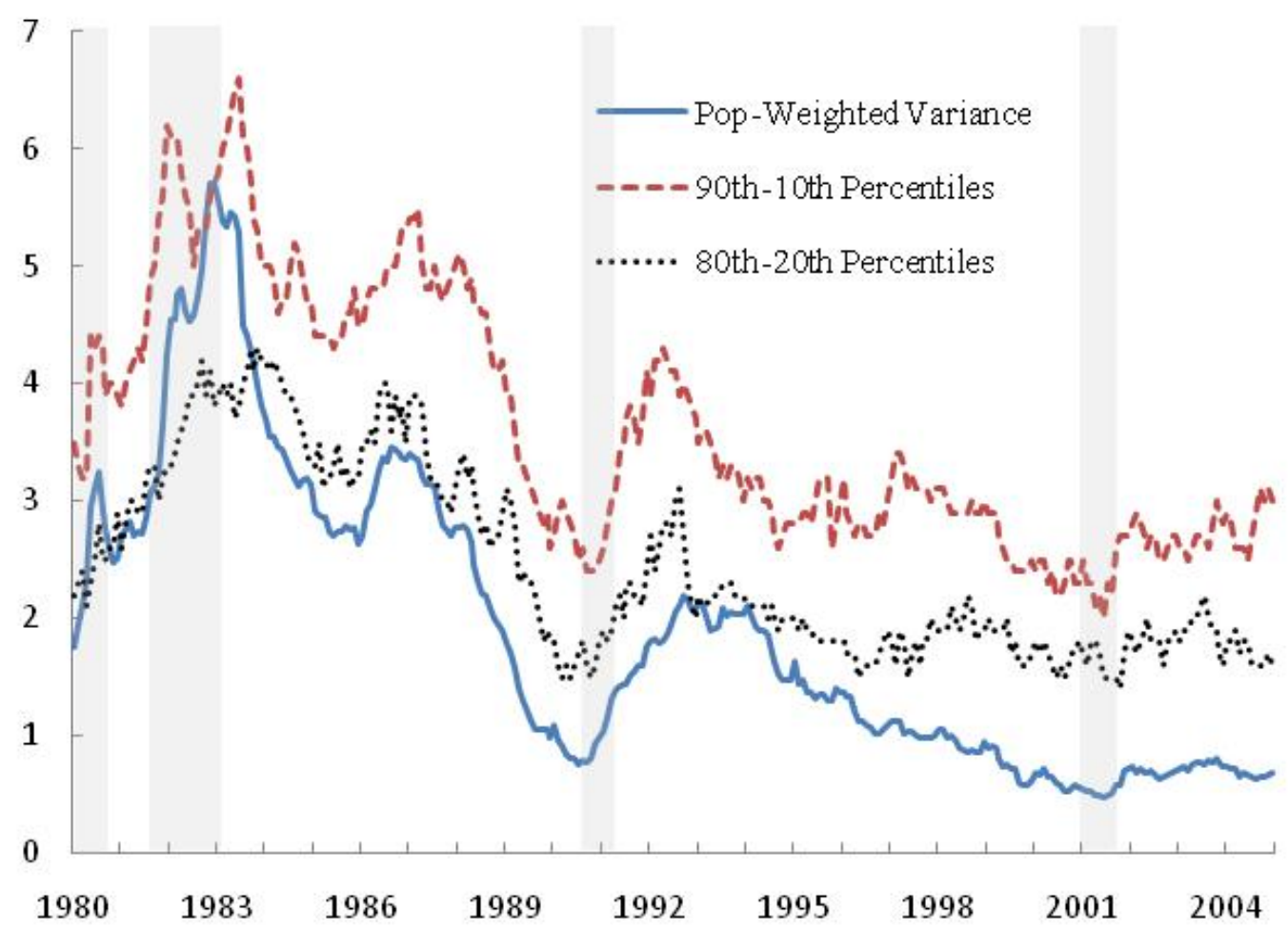

Note: The figure plots three measures of the cross-state unemployment dispersion. "Pop-Weighted Variance" is the variance of UE rates across states weighted by their respective population shares, while the other two are the difference between high and low unemployment states as measured by their percentiles in the cross-state distribution each period. Grey shaded areas are NBER-dated recessions. 
Figure 2: Cross-State Output Gap Dispersion and Selected Macroeconomic Variables

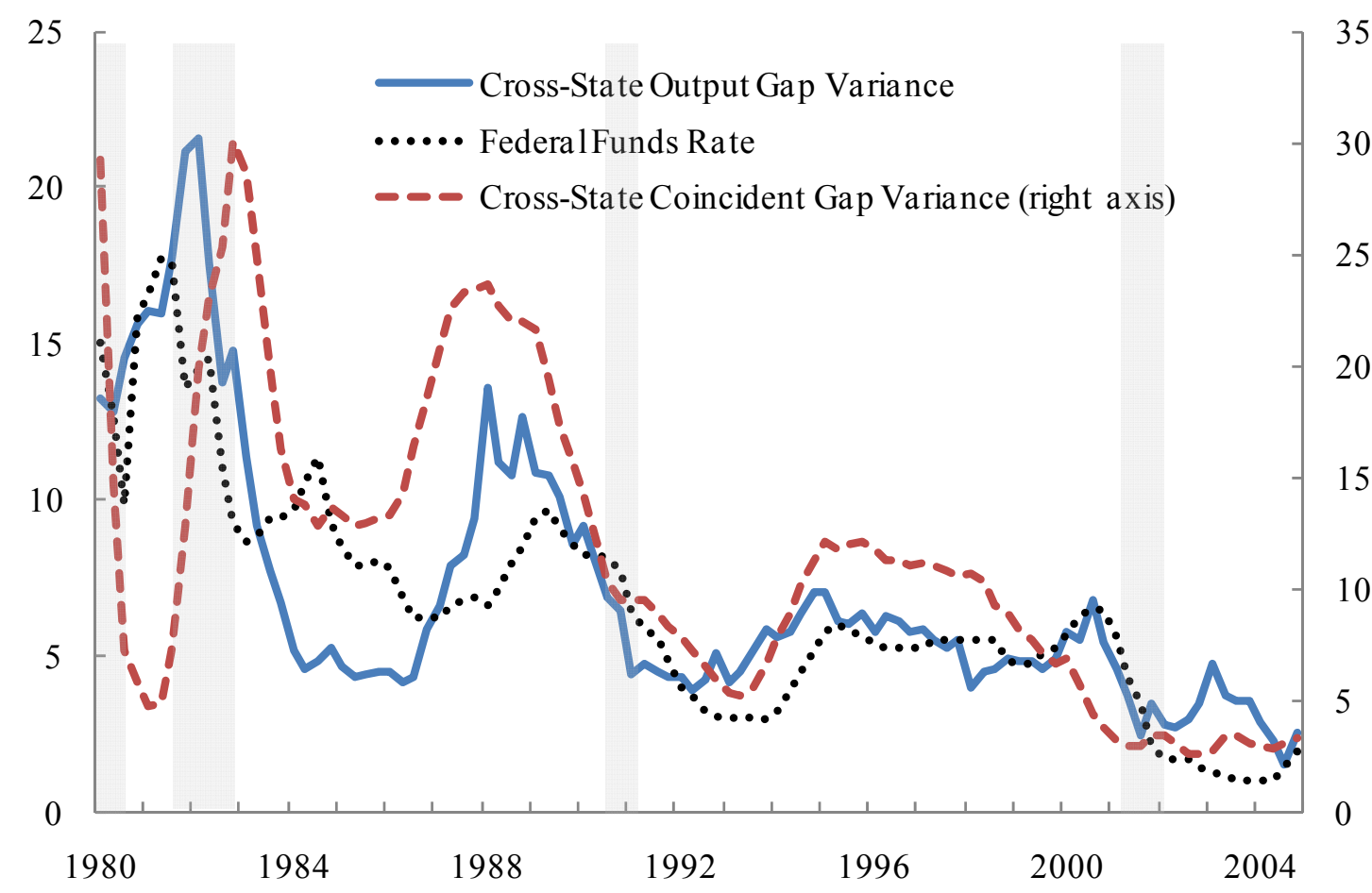

Note: The figure plots the quarterly population-weighted variance of the coincident-index gaps and output gaps across states, along with the Federal Funds Rate. Grey shaded areas are NBER-dated recessions. 
Table 1: Correlations

\begin{tabular}{lccc}
\hline \hline \multicolumn{3}{c}{ Cross-State Variances } \\
& Unemployment & Coinc. Gap & Output Gap \\
\hline Panel A: Correlation & among & Measures & of Regional Economic Disparities \\
Unemployment & 1.00 & & \\
Coinc. Gap & 0.53 & 1.00 & \multirow{2}{*}{1.00} \\
Output Gap & 0.75 & 0.76 & \\
Panel B: Correlation & with Aggregate & Variables & 0.71 \\
Federal Funds Rate & 0.61 & 0.70 & 0.51 \\
Unemployment Rate & 0.89 & 0.37 & 0.59 \\
Inflation & 0.53 & 0.66 & 0.11 \\
Real GDP Growth & 0.12 & -0.22 & \\
\hline \hline
\end{tabular}

Note: The table presents unconditional correlations between quarterly variables from 1982 to 2002 . Panel A presents correlations among three population-weighted cross-state variance measures of regional economic disparities, while Panel B presents the correlation of these measures with selected aggregate macroeconomic variables. See section 2.1 for details. 
Table 2: The Effect of Regional Economic Dispersion Measures on Interest Rate Decisions

\begin{tabular}{|c|c|c|c|c|c|c|c|c|c|c|c|c|}
\hline \multirow{3}{*}{$\begin{array}{c}\text { Regional } \\
\text { Dispersion } \\
\text { Measure: } \\
c\end{array}$} & \multirow{2}{*}{\multicolumn{2}{|c|}{ None }} & \multicolumn{2}{|c|}{$\begin{array}{c}\text { Population- } \\
\text { Weighted Cross- } \\
\text { State UE } \\
\text { Variance } \\
\end{array}$} & \multicolumn{2}{|c|}{$\begin{array}{c}90^{\text {th }} \text { Percentile - } \\
10^{\text {th }} \text { Percentile of } \\
\text { State UE } \\
\text { Distribution }\end{array}$} & \multicolumn{2}{|c|}{$\begin{array}{l}80^{\text {th }} \text { Percentile - } \\
20^{\text {th }} \text { Percentile of } \\
\text { State UE } \\
\text { Distribution }\end{array}$} & \multicolumn{2}{|c|}{$\begin{array}{c}\text { Population- } \\
\text { Weighted Cross- } \\
\text { State Coincident } \\
\text { Gap Variance }\end{array}$} & \multicolumn{2}{|c|}{$\begin{array}{c}\text { Population- } \\
\text { Weighted Cross- } \\
\text { State Output Gap } \\
\text { Variance }\end{array}$} \\
\hline & & & \multicolumn{2}{|c|}{$(2)$} & \multicolumn{2}{|c|}{ (3) } & \multicolumn{2}{|c|}{$(4)$} & \multicolumn{2}{|c|}{ (5) } & \multicolumn{2}{|c|}{ (6) } \\
\hline & 0.05 & $(0.20)$ & $0.82^{* * *}$ & $(0.23)$ & 0.18 & $(0.20)$ & 0.21 & $(0.25)$ & 0.16 & $(0.16)$ & $-0.46^{* *}$ & $(0.19)$ \\
\hline$\rho$ & $0.93^{* * *}$ & $(0.02)$ & $0.89^{* * *}$ & $(0.03)$ & $0.91^{* * *}$ & $(0.02)$ & $0.91^{* * *}$ & $(0.03)$ & $0.89^{* * *}$ & $(0.03)$ & $0.83^{* * *}$ & $(0.04)$ \\
\hline$\phi_{\pi}$ & $0.16^{* * *}$ & $(0.06)$ & $0.19^{* * *}$ & $(0.05)$ & $0.17^{* * *}$ & $(0.05)$ & $0.18^{* * *}$ & $(0.06)$ & $0.13^{* * *}$ & $(0.05)$ & $0.17^{* *}$ & (0.09) \\
\hline$\phi_{g y}$ & $0.15^{* * *}$ & $(0.02)$ & $0.11^{* * *}$ & $(0.03)$ & $0.13^{* * *}$ & $(0.03)$ & $0.13^{* * *}$ & $(0.03)$ & $0.14^{* * *}$ & $(0.03)$ & $0.29^{* * *}$ & $(0.05)$ \\
\hline$\phi_{u e}$ & $-0.09^{* * *}$ & $(0.03)$ & $-0.24^{* * * *}$ & $(0.04)$ & $-0.16^{* * *}$ & $(0.04)$ & $-0.15^{* * *}$ & $(0.05)$ & $-0.11^{* * *}$ & $(0.02)$ & $-0.10^{* *}$ & $(0.03)$ \\
\hline$\beta$ & & & $0.23^{* * *}$ & $(0.05)$ & $0.13^{* * *}$ & $(0.04)$ & $0.14^{* *}$ & $(0.07)$ & $0.03^{* * *}$ & $(0.01)$ & $0.13^{* * *}$ & $(0.03)$ \\
\hline Sample & $1983-$ & 2002 & $1983-$ & 002 & $1983-$ & 002 & $1983-$ & 002 & $1983-2$ & 002 & $1983-$ & 002 \\
\hline Frequency & FOMC $\mathrm{r}$ & leetings & FOMC $\mathrm{n}$ & eetings & FOMC $\mathrm{r}$ & eetings & FOMC $n$ & eetings & FOMC $\mathrm{m}$ & eetings & Quar & erly \\
\hline $\mathrm{N}$ & 15 & & 15 & & 15 & & 15 & & 15 & & 7 & \\
\hline
\end{tabular}

Note: The table presents OLS estimates of equations (1) and (2) in the text. $c$ is the constant term in the Taylor rule, $\rho$ is the degree of interest smoothing, $\varphi_{\pi}$ is the coefficient on expected inflation, $\varphi_{g y}$ is the coefficient on expected output growth, $\varphi_{u e}$ is the coefficient on expected unemployment rate, and $\beta$ is the coefficient on the lagged measure of regional economic dispersion. Columns 2-6 use different measures of regional economic disparities, as indicated by each header. Columns 1-5 are estimated at the frequency of FOMC meetings, while column 6 is estimated quarterly, using values from the last meeting of each quarter. Newey-West standard errors are in parentheses, and statistical significance at the $10 \%, 5 \%$, and $1 \%$ levels are indicated by a $* * *$, and $* * *$ respectively. See section 2.1 for more details. 
Table 3: Sensitivity Analysis to the Specification of the Taylor Rule

\begin{tabular}{|c|c|c|c|c|c|c|c|c|c|c|c|c|c|c|c|c|}
\hline \multirow[t]{2}{*}{ Robustness to: } & \multirow{2}{*}{\multicolumn{2}{|c|}{$\begin{array}{c}\text { Forecasting } \\
\text { Horizon of } 2 \\
\text { Quarters } \\
(1) \\
\end{array}$}} & \multirow{2}{*}{\multicolumn{2}{|c|}{$\begin{array}{c}\text { Forecasting } \\
\text { Horizon of Current } \\
\text { Quarter } \\
(2) \\
\end{array}$}} & \multicolumn{2}{|c|}{$\begin{array}{l}\text { Degree of Interest } \\
\text { Smoothing }\end{array}$} & \multicolumn{2}{|c|}{$\begin{array}{l}\text { Forecast of the } \\
\text { Output Gap }\end{array}$} & \multicolumn{2}{|c|}{$\begin{array}{c}\text { Non-Linear } \\
\text { Response to } \\
\text { Unemployment }\end{array}$} & \multicolumn{2}{|c|}{$\begin{array}{c}\text { Persistent } \\
\text { Monetary Policy } \\
\text { Shocks }\end{array}$} & \multicolumn{2}{|c|}{$\begin{array}{c}\text { IV: 3-Month } \\
\text { Ahead Dispersion }\end{array}$} & \multicolumn{2}{|c|}{$\begin{array}{c}\text { IV: 6-Month } \\
\text { Ahead Dispersion }\end{array}$} \\
\hline & & & & & $(3$ & & $(4$ & & \multicolumn{2}{|c|}{$(5)$} & \multicolumn{2}{|c|}{$(6)$} & \multicolumn{2}{|c|}{$(7)$} & \multicolumn{2}{|c|}{$(8)$} \\
\hline$\rho_{l}$ & $0.87^{* * *}$ & $(0.04)$ & $0.93^{* * *}$ & $(0.02)$ & $1.14^{* * *}$ & $(0.13)$ & $0.92^{* * *}$ & $(0.02)$ & $0.89^{* * *}$ & $(0.03)$ & $0.89^{* * *}$ & $(0.03)$ & $0.88^{* * *}$ & $(0.03)$ & $0.86^{* * *}$ & $(0.04)$ \\
\hline$\rho_{2}$ & & & & & -0.17 & $(0.25)$ & & & & & & & & & & \\
\hline$\rho_{3}$ & & & & & -0.07 & $(0.14)$ & & & & & & & & & & \\
\hline$\phi_{\pi}$ & $0.24^{* * *}$ & $(0.08)$ & $0.10^{* *}$ & $(0.04)$ & $0.16^{* * *}$ & $(0.04)$ & $0.14^{* * *}$ & $(0.05)$ & $0.20^{* * *}$ & $(0.05)$ & $0.15^{* * *}$ & $(0.05)$ & $0.21^{* * *}$ & $(0.06)$ & $0.25^{* * *}$ & $(0.07)$ \\
\hline$\phi_{g y}$ & 0.04 & $(0.03)$ & $0.12^{* * *}$ & $(0.02)$ & $0.09^{* * *}$ & $(0.03)$ & $0.13^{* * *}$ & $(0.02)$ & $0.11^{* * *}$ & $(0.03)$ & $0.10^{* * *}$ & $(0.03)$ & $0.13^{* * *}$ & $(0.03)$ & $0.14^{* * *}$ & $(0.03)$ \\
\hline$\phi_{u e}$ & $-0.31^{* * *}$ & $(0.07)$ & $-0.13^{* * *}$ & $(0.04)$ & $-0.19^{* * *}$ & $(0.04)$ & & & $-0.41^{* *}$ & $(0.20)$ & $-0.26^{* * *}$ & $(0.06)$ & $-0.29^{* * *}$ & $(0.06)$ & $-0.40^{* * *}$ & $(0.09)$ \\
\hline$\phi_{x}$ & & & & & & & $0.08^{* * *}$ & $(0.02)$ & & & & & & & & \\
\hline$\phi_{u e 2}$ & & & & & & & & & 0.01 & $(0.02)$ & & & & & & \\
\hline$\rho_{1}^{\varepsilon}$ & & & & & & & & & & & $0.25^{*}$ & $(0.14)$ & & & & \\
\hline$\beta$ & $0.30^{* * *}$ & $(0.07)$ & $0.12^{* *}$ & $(0.05)$ & $0.18^{* * *}$ & $(0.04)$ & $0.17^{* * *}$ & $(0.05)$ & $0.23^{* * *}$ & $(0.05)$ & $0.26^{* * *}$ & $(0.07)$ & $0.30^{* * *}$ & $(0.08)$ & $0.47^{* * *}$ & $(0.14)$ \\
\hline $\begin{array}{c}\text { Forecasting Horizon } \\
\text { Sample }\end{array}$ & $\begin{array}{r}\text { 2-Quarter } \\
1983-\end{array}$ & $\begin{array}{l}\text { Ahead } \\
002\end{array}$ & $\begin{array}{r}\text { Current } \\
1983-\end{array}$ & $\begin{array}{l}\text { Quarter } \\
002\end{array}$ & $\begin{array}{r}\text { 1-Quarte } \\
1983-?\end{array}$ & $\begin{array}{l}\text { Ahead } \\
002\end{array}$ & $\begin{array}{r}\text { 1-Quarte } \\
1983-\end{array}$ & $\begin{array}{l}\text { Ahead } \\
002\end{array}$ & $\begin{array}{r}\text { 1-Quarte } \\
1983-\end{array}$ & $\begin{array}{l}\text { Ahead } \\
2002\end{array}$ & $\begin{array}{r}\text { 1-Quarte } \\
1983-\end{array}$ & $\begin{array}{l}\text { Ahead } \\
2002\end{array}$ & $\begin{array}{r}\text { 1-Quarter } \\
1983-2\end{array}$ & $\begin{array}{l}\text { Ahead } \\
002\end{array}$ & $\begin{array}{r}\text { 1-Quarte } \\
1983-\end{array}$ & $\begin{array}{l}\text { Ahead } \\
2002\end{array}$ \\
\hline Frequency & FOMC n & eetings & FOMC $\mathrm{r}$ & leetings & FOMC n & eetings & FOMC $r$ & leetings & FOMC $\mathrm{r}$ & neetings & FOMC $\mathrm{r}$ & neetings & FOMC n & eetings & FOMC $r$ & neetings \\
\hline $\mathrm{N}$ & 15 & & 15 & & 15 & & 15 & & 15 & & 15 & & 15 & & 15 & \\
\hline
\end{tabular}

Note: The table presents OLS estimates of the augmented Taylor rule (2) under alternative specifications. $\rho_{i}\left(\rho_{i}^{\varepsilon}\right)$ is the $i$-th degree of interest smoothing (persistent monetary policy shocks), $\varphi_{\pi}, \varphi_{g y}, \varphi_{u e}, \varphi_{u e 2}, \varphi_{x}$, and $\beta$ are the coefficients on expected inflation, output growth, unemployment, unemployment squared, the output gap, and the lag of the population weighted cross-state variance of unemployment rates. Newey-West standard errors are in parentheses, and statistical significance at the $10 \%, 5 \%$, and $1 \%$ levels are indicated by a *,*, and *** respectively. See section 2.2 for more details. 
Table 4: Sensitivity Analysis to the Specification of the Taylor Rule

\begin{tabular}{|c|c|c|c|c|c|c|c|c|c|c|c|c|c|c|}
\hline \multirow[b]{3}{*}{$c$} & \multirow{2}{*}{\multicolumn{2}{|c|}{ Whole Sample }} & \multirow{2}{*}{\multicolumn{2}{|c|}{ First Sub-Sample }} & \multirow{2}{*}{\multicolumn{2}{|c|}{ Second Sub-Sample }} & \multirow{2}{*}{\multicolumn{2}{|c|}{$\begin{array}{c}\begin{array}{c}\text { Dropping } \\
\text { Recessions }\end{array} \\
(4) \\
\end{array}$}} & \multirow{2}{*}{\multicolumn{2}{|c|}{$\begin{array}{c}\begin{array}{c}\text { Dropping } \\
\text { Recoveries }\end{array} \\
(5) \\
\end{array}$}} & \multirow{2}{*}{\multicolumn{2}{|c|}{$\begin{array}{c}\text { Dropping } \\
\text { Recessions and } \\
\text { Recoveries } \\
(6)\end{array}$}} & \multirow{2}{*}{\multicolumn{2}{|c|}{$\begin{array}{l}\text { Only Recessions } \\
\text { and Recoveries } \\
(7)\end{array}$}} \\
\hline & & & & & & & & & & & & & & \\
\hline & $0.82^{* * *}$ & $(0.23)$ & 0.91 & $(0.55)$ & $0.95^{*}$ & $(0.53)$ & $0.89^{* * *}$ & $(0.24)$ & $0.99^{* * *}$ & $(0.33)$ & $1.01^{* * *}$ & $(0.34)$ & 1.05 & $(0.85)$ \\
\hline$\rho$ & $0.89^{* * *}$ & $(0.03)$ & $0.91^{* * *}$ & $(0.04)$ & $0.88^{* * *}$ & $(0.05)$ & $0.90^{* * *}$ & $(0.02)$ & $0.87^{* * *}$ & $(0.03)$ & $0.87^{* * *}$ & $(0.02)$ & $0.90^{* * *}$ & $(0.06)$ \\
\hline$\phi_{\pi}$ & $0.19^{* * *}$ & $(0.05)$ & 0.14 & (0.09) & $0.22^{* * *}$ & $(0.07)$ & $0.15^{* * *}$ & $(0.06)$ & $0.23^{* * *}$ & $(0.06)$ & $0.19^{* * *}$ & $(0.06)$ & $0.19^{* *}$ & $(0.09)$ \\
\hline$\phi_{g y}$ & $0.11^{* * *}$ & $(0.03)$ & $0.11^{*}$ & $(0.04)$ & $0.09^{* * *}$ & $(0.03)$ & $0.12^{* * *}$ & $(0.02)$ & $0.10^{* * *}$ & $(0.03)$ & $0.08^{* * *}$ & $(0.04)$ & $0.08^{* *}$ & $(0.03)$ \\
\hline$\phi_{u e}$ & $-0.24^{* * *}$ & $(0.04)$ & $-0.25^{* * *}$ & $(0.06)$ & $-0.28^{* * *}$ & $(0.10)$ & $-0.24^{* * *}$ & $(0.04)$ & $-0.24^{* * *}$ & $(0.05)$ & $-0.21^{* * *}$ & $(0.05)$ & $-0.30^{*}$ & $(0.15)$ \\
\hline$\beta$ & $0.23^{* * *}$ & $(0.05)$ & $0.21^{* * *}$ & $(0.05)$ & $0.38^{* * *}$ & $(0.13)$ & $0.23^{* * *}$ & $(0.05)$ & $0.18^{* * *}$ & $(0.05)$ & $0.14^{* * *}$ & $(0.05)$ & $0.37^{* *}$ & $(0.16)$ \\
\hline Sample & 1983 & 2002 & 1983 & 992 & 1993 & 002 & 1983 & 002 & 1983 & 002 & 1983 & 002 & 1983 & 002 \\
\hline Frequency & $\mathrm{FOMC}_{1}$ & leetings & $\mathrm{FOMC}_{1}$ & eetings & FOMC & eetings & $\mathrm{FOMC}_{1}$ & eetings & $\mathrm{FOMC}_{1}$ & eetings & FOMC & eetings & FOMC & eetings \\
\hline $\mathrm{N}$ & 15 & & 7 & & 8 & & 14 & & 12 & & 1 & & & \\
\hline
\end{tabular}

Note: The table presents OLS estimates of the augmented Taylor rule (2) for different time periods. $\rho$ is the degree of interest smoothing, while $\varphi_{\pi}$, $\varphi_{g y}, \varphi_{u e}, \varphi_{u e 2}, \varphi_{x}$, and $\beta$ are the coefficients on expected inflation, output growth, unemployment, unemployment squared, the output gap, and the lag of the population weighted cross-state variance of unemployment rates. Recessions are dated using NBER business cycle dates and Recoveries are defined as the 18 months following recessions. Newey-West standard errors are in parentheses, and statistical significance at the $10 \%, 5 \%$, and $1 \%$ levels are indicated by $\mathrm{a} * * *$, and $* * *$ respectively. See section 2.2 for more details. 
Table 5: Robustness to Controlling for Macroeconomic Shocks and Leading Indicators

\begin{tabular}{|c|c|c|c|c|c|c|c|c|c|c|}
\hline \multicolumn{11}{|c|}{ Panel A: Controlling for Macroeconomic Shocks } \\
\hline \multirow{2}{*}{$\begin{array}{l}\text { Controlling for: } \\
\text { Lag } 1 \text { of Shock }\end{array}$} & \multicolumn{2}{|c|}{ Technology Shocks } & \multicolumn{2}{|c|}{ News Shocks } & \multicolumn{2}{|c|}{ Uncertainty Shocks } & \multicolumn{2}{|c|}{ Oil Price Shocks } & \multicolumn{2}{|c|}{ Tax Shocks } \\
\hline & -0.08 & $(0.06)$ & -0.10 & $(0.65)$ & $-0.03^{* * *}$ & $(0.01)$ & 0.77 & $(2.06)$ & -0.28 & $(0.24)$ \\
\hline Lag 2 of Shock & -0.07 & $(0.07)$ & 0.34 & $(0.58)$ & $0.02^{*}$ & $(0.01)$ & -2.53 & $(1.60)$ & -0.18 & $(0.27)$ \\
\hline Lag 3 of Shock & 0.02 & $(0.08)$ & -0.33 & $(0.51)$ & 0.00 & $(0.01)$ & -1.24 & $(1.30)$ & $0.83^{*}$ & $(0.48)$ \\
\hline Lag 4 of Shock & -0.08 & $(0.07)$ & -0.44 & $(0.55)$ & 0.01 & $(0.01)$ & 0.36 & $(1.39)$ & -0.06 & $(0.23)$ \\
\hline$\beta$ & $0.42^{* * *}$ & $(0.08)$ & $0.46^{* * *}$ & $(0.09)$ & $0.47^{* * *}$ & $(0.09)$ & $0.41^{* * *}$ & $(0.10)$ & $0.45^{* * *}$ & $(0.08)$ \\
\hline Sample & \multicolumn{2}{|c|}{ 1983-2002 } & \multicolumn{2}{|c|}{$1983-2002$} & \multicolumn{2}{|c|}{$1983-2002$} & \multicolumn{2}{|c|}{$1983-2002$} & \multicolumn{2}{|c|}{ 1983-2002 } \\
\hline Frequency & \multicolumn{2}{|c|}{ Quarterly } & \multicolumn{2}{|c|}{ Quarterly } & \multicolumn{2}{|c|}{ Quarterly } & \multicolumn{2}{|c|}{ Quarterly } & \multicolumn{2}{|c|}{ Quarterly } \\
\hline $\mathrm{N}$ & \multicolumn{2}{|c|}{79} & \multicolumn{2}{|c|}{79} & \multicolumn{2}{|c|}{79} & \multicolumn{2}{|c|}{79} & \multicolumn{2}{|c|}{79} \\
\hline \multicolumn{11}{|c|}{ Panel B: Controlling for Leading Indicators and Other Factors } \\
\hline Controlling for: & \multicolumn{2}{|c|}{$\begin{array}{l}\text { Consumer } \\
\text { Confidence } \\
\end{array}$} & \multicolumn{2}{|c|}{ Stock Prices } & \multicolumn{2}{|c|}{$\begin{array}{c}\text { Producer Price } \\
\text { Inflation } \\
\end{array}$} & \multicolumn{2}{|c|}{ Coincident Index } & \multicolumn{2}{|c|}{$\begin{array}{c}\text { Quadratic Time } \\
\text { Trend }^{\mathrm{a}} \\
\end{array}$} \\
\hline Lag 1 & -0.01 & $(0.55)$ & 0.33 & $(0.36)$ & $0.05^{* *}$ & $(0.02)$ & 0.08 & $(0.14)$ & 0.00 & $(0.01)$ \\
\hline Lag 2 & $0.96^{*}$ & $(0.57)$ & -0.57 & (0.69) & -0.02 & $(0.03)$ & 0.14 & $(0.21)$ & 0.00 & $(0.000)$ \\
\hline Lag 3 & -0.56 & $(0.66)$ & -0.07 & $(0.70)$ & -0.03 & $(0.03)$ & $-0.55^{* *}$ & $(0.24)$ & & \\
\hline Lag 4 & -0.46 & $(0.63)$ & 0.18 & $(0.39)$ & 0.01 & $(0.02)$ & 0.30 & $(0.19)$ & & \\
\hline$\beta$ & $0.23^{* * *}$ & $(0.07)$ & $0.19^{* * *}$ & $(0.06)$ & $0.21^{* * *}$ & $(0.05)$ & $0.19^{* *}$ & $(0.08)$ & $0.22^{* *}$ & $(0.09)$ \\
\hline Sample & 1983 & 2002 & 1983 & 2002 & 1983 & 2002 & 1983 & 2002 & 198 & 2002 \\
\hline Frequency & FOMC & leetings & FOMC & neetings & FOMC & neetings & FOMC & neetings & FOMC & neetings \\
\hline $\mathrm{N}$ & & & & & 15 & & & & & \\
\hline
\end{tabular}

Note: Panel A presents estimates of Taylor rule (3) which includes 4 lags of macroeconomic shocks and the cross-state population-weighted variance of unemployment rates. Only the coefficients on the lagged shocks and the regional dispersion measure $(\beta)$ are reported. Panel B presents estimates of Taylor rule (3) which includes 4 lags of leading indicators and the cross-state population-weighted variance of unemployment rates. Only the coefficients on the lagged values of the leading indicators and the regional dispersion measure $(\beta)$ are reported. In the last column of Panel B (quadratic time trend), the coefficients on Lag 1 and Lag 2 refer to the estimates on the linear and quadratic component of the time trend respectively. Newey-West standard errors are in parentheses, and statistical significance at the $10 \%, 5 \%$, and $1 \%$ levels are indicated by $a^{*}, * *$, and $* * *$ respectively. See section 2.3 for more details. 
Table 6: Testing for a Differential Response by the Central Bank to Regional Economic Slackness

\begin{tabular}{|c|c|c|c|c|c|c|c|c|c|c|c|c|}
\hline & \multicolumn{4}{|c|}{ Using State Unemployment Rates } & \multicolumn{4}{|c|}{ Using State Coincident Index Gaps } & \multicolumn{4}{|c|}{ Using State Output Gaps } \\
\hline & \multicolumn{2}{|c|}{$(1)$} & \multicolumn{2}{|c|}{$(2)$} & \multicolumn{2}{|c|}{ (3) } & \multicolumn{2}{|c|}{$(4)$} & \multicolumn{2}{|c|}{$(5)$} & \multicolumn{2}{|c|}{$(6)$} \\
\hline$c$ & 0.22 & $(0.21)$ & 0.27 & $(0.23)$ & -0.04 & $(0.15)$ & -0.18 & $(0.18)$ & -0.44 & $(0.48)$ & $-0.88^{*}$ & $(0.45)$ \\
\hline$\rho$ & $0.92^{* * *}$ & $(0.03)$ & $0.93^{* * *}$ & $(0.03)$ & $0.91^{* * *}$ & $(0.02)$ & $0.92^{* * *}$ & $(0.03)$ & $0.84^{* * *}$ & $(0.05)$ & $0.85^{* * *}$ & $(0.05)$ \\
\hline$\phi_{\pi}$ & $0.16^{* * *}$ & $(0.05)$ & $0.17^{* * *}$ & $(0.06)$ & $0.12^{* *}$ & $(0.05)$ & $0.13^{* * *}$ & $(0.05)$ & $0.22^{* * *}$ & $(0.08)$ & $0.19^{* *}$ & (0.09) \\
\hline$\phi_{g y}$ & $0.12^{* * *}$ & $(0.03)$ & $0.10^{* * *}$ & $(0.03)$ & $0.14^{* * *}$ & $(0.03)$ & $0.15^{* * *}$ & $(0.03)$ & $0.27^{* * *}$ & $(0.05)$ & $0.27^{* * *}$ & $(0.05)$ \\
\hline$\phi_{u e}$ & $-0.19^{* * *}$ & $(0.06)$ & $-0.22^{* * *}$ & $(0.05)$ & $-0.10^{* * *}$ & $(0.03)$ & $-0.08^{* * *}$ & $(0.03)$ & $-0.14^{* *}$ & $(0.07)$ & -0.09 & $(0.06)$ \\
\hline 90th-Mean & 0.07 & $(0.08)$ & & & $0.09^{* * *}$ & $(0.03)$ & & & $0.25^{* * *}$ & $(0.08)$ & & \\
\hline 10th-Mean & $-0.24^{*}$ & $(0.13)$ & & & 0.00 & $(0.03)$ & & & -0.04 & $(0.09)$ & & \\
\hline 80th-Mean & & & -0.10 & $(0.14)$ & & & $0.09^{* * *}$ & $(0.03)$ & & & $0.36^{* *}$ & $(0.15)$ \\
\hline 20th-Mean & & & $-0.46^{* * *}$ & $(0.16)$ & & & -0.03 & $(0.03)$ & & & $-0.12^{*}$ & $(0.09)$ \\
\hline Null of equality: & \multicolumn{2}{|c|}{$9.6^{* * *}$} & \multicolumn{2}{|c|}{$7.1^{* * *}$} & \multicolumn{2}{|c|}{$23.3^{* * *}$} & \multicolumn{2}{|c|}{$20.7^{* * *}$} & \multicolumn{2}{|c|}{$7.6^{* * *}$} & \multicolumn{2}{|c|}{$6.3^{* *}$} \\
\hline Sample & \multicolumn{2}{|c|}{ 1983-2002 } & \multicolumn{2}{|c|}{ 1983-2002 } & \multicolumn{2}{|c|}{ 1983-2002 } & \multicolumn{2}{|c|}{ 1983-2002 } & \multicolumn{2}{|c|}{$1983-2002$} & \multicolumn{2}{|c|}{$1983-2002$} \\
\hline Frequency & \multicolumn{2}{|c|}{ FOMC meetings } & \multicolumn{2}{|c|}{ FOMC meetings } & \multicolumn{2}{|c|}{ FOMC meetings } & \multicolumn{2}{|c|}{ FOMC meetings } & \multicolumn{2}{|c|}{ Quarterly } & \multicolumn{2}{|c|}{ Quarterly } \\
\hline $\mathrm{N}$ & \multicolumn{2}{|c|}{158} & \multicolumn{2}{|c|}{158} & \multicolumn{2}{|c|}{158} & \multicolumn{2}{|c|}{158} & \multicolumn{2}{|c|}{79} & \multicolumn{2}{|c|}{79} \\
\hline
\end{tabular}

Note: The table presents estimates of equation (8) in the text. " $90^{\text {th }}$-Mean" is the coefficient on the difference between the $90^{\text {th }}$ percentile relative to the population weighted average of the state distribution of unemployment rates (columns 1 and 2), coincident index gaps measures (columns 3 and 4) or output gaps (columns 5 and 6), with other coefficients defined in the same manner for their respective percentiles. "Null of equality" is the test statistic for the hypothesis that the coefficients on the two included percentile differentials are equal. Newey-West standard errors are in parentheses, and statistical significance at the $10 \%, 5 \%$, and $1 \%$ levels are indicated by a $* * *$, and $* * *$ respectively. See section 3 for more details. 
Table 7: Testing Alternative Theoretical Explanations

\begin{tabular}{|c|c|c|c|c|c|c|c|c|c|c|c|c|}
\hline & \multicolumn{4}{|c|}{ Loss-Sharing } & \multicolumn{4}{|c|}{ Regional MP effects } & \multicolumn{4}{|c|}{ Voting Representation } \\
\hline & \multirow{2}{*}{\multicolumn{2}{|c|}{$\begin{array}{c}\text { Using UE rates } \\
(1)\end{array}$}} & \multirow{2}{*}{\multicolumn{2}{|c|}{$\begin{array}{c}\text { Using Output Gaps } \\
(2)\end{array}$}} & \multirow{2}{*}{\multicolumn{2}{|c|}{$\begin{array}{c}\text { State-Sensitivity } \\
(3)\end{array}$}} & \multirow{2}{*}{\multicolumn{2}{|c|}{$\begin{array}{c}\text { Regional Sensitivity } \\
(4)\end{array}$}} & \multirow{2}{*}{\multicolumn{2}{|c|}{$\begin{array}{c}\text { Using UE rates } \\
(5)\end{array}$}} & \multirow{2}{*}{\multicolumn{2}{|c|}{$\begin{array}{c}\text { Using Output Gaps } \\
(6)\end{array}$}} \\
\hline & & & & & & & & & & & & \\
\hline$c$ & $0.97^{* * *}$ & $(0.26)$ & -0.80 & $(0.51)$ & $0.87^{* *}$ & $(0.39)$ & $0.70^{*}$ & $(0.40)$ & $0.72^{* * *}$ & $(0.26)$ & -0.20 & $(0.23)$ \\
\hline$\rho$ & $0.89^{* * *}$ & $(0.02)$ & $0.83^{* * *}$ & $(0.04)$ & $0.89^{* * *}$ & $(0.03)$ & $0.90^{* * *}$ & $(0.03)$ & $0.91^{* * *}$ & $(0.02)$ & $0.83^{* * *}$ & $(0.05)$ \\
\hline$\phi_{\pi}$ & $0.20^{* * *}$ & $(0.05)$ & $0.19^{*}$ & $(0.11)$ & $0.19^{* * *}$ & $(0.05)$ & $0.18^{* * *}$ & (0.06) & $0.12^{* *}$ & $(0.05)$ & 0.13 & $(0.10)$ \\
\hline$\phi_{g y}$ & $0.10^{* * *}$ & $(0.03)$ & $0.28^{* * *}$ & $(0.05)$ & $0.10^{* * *}$ & $(0.03)$ & $0.11^{* * *}$ & $(0.03)$ & $0.10^{* * *}$ & $(0.03)$ & $0.26^{* * *}$ & $(0.06)$ \\
\hline$\phi_{u e}$ & $-0.28^{* * *}$ & $(0.06)$ & -0.06 & $(0.08)$ & $-0.25^{* * *}$ & $(0.07)$ & $-0.23^{* * *}$ & $(0.07)$ & $-0.20^{* * *}$ & $(0.05)$ & $-0.10^{* *}$ & $(0.04)$ \\
\hline Variance & $0.29^{* * *}$ & $(0.10)$ & $0.12^{* * *}$ & $(0.03)$ & $0.26^{* * *}$ & $(0.08)$ & $0.25^{* * *}$ & $(0.07)$ & $0.23^{* * *}$ & $(0.06)$ & $0.12^{* * *}$ & $(0.03)$ \\
\hline Skew & -0.09 & $(0.08)$ & -0.02 & $(0.04)$ & & & & & & & & \\
\hline Variance*Skew & 0.02 & $(0.02)$ & 0.001 & $(0.003)$ & & & & & & & & \\
\hline Highly Sensitive to MP & & & & & -0.03 & $(0.06)$ & -0.06 & $(0.06)$ & & & & \\
\hline Insensitive to MP & & & & & -0.03 & $(0.05)$ & -0.01 & $(0.07)$ & & & & \\
\hline Voting-Share Dispersion & & & & & & & & & 0.32 & $(0.21)$ & -0.08 & $(0.17)$ \\
\hline Sample & 1983 & 002 & 1983 & 002 & 1983 & 002 & 1983 & 002 & 1983 & 000 & 1983 & 000 \\
\hline Frequency & FOMC & eetings & Qua & erly & FOMC & eetings & FOMC 1 & eetings & FOMC & eetings & Qua & erly \\
\hline $\mathrm{N}$ & & & & & & & 15 & & 1 & & & \\
\hline
\end{tabular}

Note: The table presents estimates of augmented Taylor rules in the text. "Variance" and "Skew" are coefficients on cross-state dispersion of unemployment rates (column 1) or output gaps (column 2) as described in section 4.1. "Highly Sensitive to MP" and "Insensitive to MP" are coefficients on population-weighted unemployment gaps for states (column 3) or regions (column 4) which are either particularly sensitive or insensitive to monetary policy as described in section 4.2. "Voting Share Dispersion" is the coefficient on the regional dispersion series constructed using weights of regional voting representation at FOMC meetings as described in section 4.3. Newey-West standard errors are in parentheses, and statistical significance at the $10 \%, 5 \%$, and $1 \%$ levels are indicated by a *,**, and *** respectively. 


\section{Appendix 1: Proofs}

\section{Proof of Proposition 1:}

Note that all summations are over the $i=1: I$ regions. The optimal policy must satisfy

$$
\pi=\alpha \lambda(u-\bar{u}) \sum \omega_{i} \frac{u_{i}^{1+\beta}}{(1-\beta) u_{i}+\beta u^{*}}
$$

Given an initial distribution of shocks $\varepsilon_{i}$ such that regional unemployment rates are not perfectly equalized across states, we want to characterize the change in optimal policy after a change in shocks which will increase economic disparities.

First, take the total derivative of the optimal policy function, which yields

$$
\frac{d \pi}{\alpha \lambda}=d u\left(\sum \omega_{i} \frac{u_{i}^{1+\beta}}{(1-\beta) u_{i}+\beta u^{*}}\right)+\beta(u-\bar{u}) \sum \omega_{i} u_{i}^{\beta}\left[\frac{(1-\beta) u_{i}+(1+\beta) u^{*}}{\left((1-\beta) u_{i}+\beta u^{*}\right)^{2}}\right] d u_{i}
$$

Taking the total derivative of the Phillips curve and treating expectations as given yields

and from the equation for aggregate unemployment

$$
d u_{i}=-\alpha \frac{u_{i}^{1+\beta}}{(1-\beta) u_{i}+\beta u^{*}}\left(d \pi-d \varepsilon_{i}\right)
$$

$$
d u=\sum \omega_{i} d u_{i}
$$

Combining these three expressions yields the following expression for the change in policy $d \pi$ as a function of the changes in the shocks $\varepsilon_{i}$

$$
\begin{aligned}
d \pi\left[\frac{1}{\lambda \alpha^{2}}+\left(\sum\right.\right. & \left.\left.\omega_{i} \frac{u_{i}^{1+\beta}}{(1-\beta) u_{i}+\beta u^{*}}\right)^{2}+\beta(u-\bar{u}) \sum \omega_{i} u_{i}^{1+2 \beta}\left[\frac{(1-\beta) u_{i}+(1+\beta) u^{*}}{\left((1-\beta) u_{i}+\beta u^{*}\right)^{3}}\right]\right] \\
= & \left(\sum \omega_{i} \frac{u_{i}^{1+\beta}}{(1-\beta) u_{i}+\beta u^{*}}\right) \sum \omega_{i} \frac{u_{i}^{1+\beta}}{(1-\beta) u_{i}+\beta u^{*}} d \varepsilon_{i} \\
& +\beta(u-\bar{u}) \sum \omega_{i} u_{i}^{1+2 \beta}\left[\frac{(1-\beta) u_{i}+(1+\beta) u^{*}}{\left((1-\beta) u_{i}+\beta u^{*}\right)^{3}}\right] d \varepsilon_{i}
\end{aligned}
$$

For Proposition 1, we want to alter the shocks to states 1 and 2 where $u_{1}<u<u_{2}$ in a way that would leave the aggregate unemployment rate unchanged in the absence of a policy change. This requires that

so that $d \varepsilon_{1}$ and $d \varepsilon_{2}$ must therefore satisfy

$$
\left.d u\right|_{d \pi=0}=\left.\sum \omega_{i} d u_{i}\right|_{d \pi=0}=-\alpha \sum \omega_{i} \frac{u_{i}^{1+\beta}}{(1-\beta) u_{i}+\beta u^{*}} d \varepsilon_{i}=0
$$

$$
d \varepsilon_{2}=-\frac{\omega_{1}}{\omega_{2}}\left(\frac{u_{1}}{u_{2}}\right)^{1+\beta}\left[\frac{(1-\beta) u_{2}+\beta u^{*}}{(1-\beta) u_{1}+\beta u^{*}}\right] d \varepsilon_{1}
$$

where $d \varepsilon_{1}<0$. Plugging this expression into the equation for the change in policy, setting all other $d \varepsilon_{i}$ equal to zero other than for states 1 and 2 yields

where

$$
M d \pi=\frac{\omega_{1} \beta(u-\bar{u}) u_{1}^{1+2 \beta}}{(1-\beta) u_{1}+\beta u^{*}} A d \varepsilon_{1}
$$

$$
M=\left[\frac{1}{\lambda \alpha^{2}}+\left(\sum \omega_{i} \frac{u_{i}^{1+\beta}}{(1-\beta) u_{i}+\beta u^{*}}\right)^{2}+\beta(u-\bar{u}) \sum \omega_{i} u_{i}^{1+2 \beta}\left[\frac{(1-\beta) u_{i}+(1+\beta) u^{*}}{\left((1-\beta) u_{i}+\beta u^{*}\right)^{3}}\right]\right]
$$

and $M>0$ if $u-\bar{u}>0$. 


$$
A=\frac{(1-\beta) u_{1}+(1+\beta) u^{*}}{\left((1-\beta) u_{1}+\beta u^{*}\right)^{2}}-\left(\frac{u_{2}}{u_{1}}\right)^{\beta} \frac{(1-\beta) u_{2}+(1+\beta) u^{*}}{\left((1-\beta) u_{2}+\beta u^{*}\right)^{2}}
$$

Given $u_{1}>0, u^{*}>0, d \varepsilon_{1}<0$, the sign of the policy change will depend on $\beta$ and $A$ if $u-\bar{u}>0$. First, when $\beta=0$, i.e. there are no nonlinearities, then optimal policy is unchanged with the increase in regional economic disparities $(d \pi=0)$. For $A$, consider

$$
A(\beta=0)=\frac{u_{1}+u^{*}}{u_{1}^{2}}-\frac{u_{2}+u^{*}}{u_{2}^{2}}=\frac{u_{1}+u^{*}}{u_{1}^{2}}-\frac{\kappa u_{1}+u^{*}}{\kappa^{2} u_{1}^{2}}=\frac{u_{1} \kappa(\kappa-1)+u^{*}\left(\kappa^{2}-1\right)}{\kappa^{2} u_{1}^{2}}>0
$$

where $\kappa \equiv \frac{u_{2}}{u_{1}}>1$. Also, we have

$$
A(\beta=1)=\frac{2 u^{*}}{u^{* 2}}-\kappa \frac{2 u^{*}}{u^{* 2}}=\frac{2}{u^{*}}(1-\kappa)<0
$$

This implies that there exists a $\bar{\beta}$ such that $\forall \beta \in(0, \bar{\beta}), A>0$. Then, combined with $u-\bar{u}>0$, this implies that $d \pi<0$ as stated in Proposition 1. Furthermore, there also exists a $\overline{\bar{\beta}} \geq \bar{\beta}$ such that $\forall \beta \in$ $(\overline{\bar{\beta}}, 1], A<0$. Then, combined with $u-\bar{u}>0$, this implies that $d \pi>0$ as stated in footnote 17 .

For Corollary 1, the optimal policy change given a single $d \varepsilon_{i}$ is

$$
\begin{aligned}
M d \pi_{i}=\left(\sum \omega_{i} \frac{u_{i}^{1+\beta}}{(1-\beta) u_{i}+\beta u^{*}}\right) \omega_{i} \frac{u_{i}^{1+\beta}}{(1-\beta) u_{i}+\beta u^{*}} d \varepsilon_{i} \\
+\beta(u-\bar{u}) \omega_{i} u_{i}^{1+2 \beta}\left[\frac{(1-\beta) u_{i}+(1+\beta) u^{*}}{\left((1-\beta) u_{i}+\beta u^{*}\right)^{3}}\right] d \varepsilon_{i}
\end{aligned}
$$

We consider shocks to states 1 and 2 where $u_{1}<u_{2}$ such that the effects on aggregate unemployment, in the absence of a policy response, are identical so

$$
d \varepsilon_{2}=\frac{\omega_{1}}{\omega_{2}}\left(\frac{u_{1}}{u_{2}}\right)^{1+\beta}\left[\frac{(1-\beta) u_{2}+\beta u^{*}}{(1-\beta) u_{1}+\beta u^{*}}\right] d \varepsilon_{1}
$$

and $d \varepsilon_{i}>0$ for $i=1,2$. Then it follows that

$$
d \pi_{2}=d \pi_{1}-\frac{A \beta(u-\bar{u}) \omega_{1} u_{1}^{1+2 \beta}}{M\left((1-\beta) u_{1}+\beta u^{*}\right)} d \varepsilon_{1}
$$

Thus, when $\beta \in(0, \bar{\beta}), A>0$ so $d \pi_{2}<d \pi_{1}$ if $u-\bar{u}>0$, which is the result in Corollary 1.

\section{Proof of Proposition 2:}

The aggregate loss function is given by

$$
L=\sum_{i} \omega_{i} L_{i}+\frac{\kappa}{2} \sum_{i} \omega_{i}\left(L_{i}-\sum_{j} \omega_{j} L_{j}\right)^{2}
$$

where $L_{i}=\frac{\pi_{i}^{2}}{2}+\frac{\lambda}{2}\left(u_{i}-\bar{u}\right)^{2}$ and $\pi_{i}=\pi+v_{i}$ and $\pi_{i}=\pi^{e}-\frac{1}{\alpha}\left(u_{i}-u^{*}\right)+\varepsilon_{a}$. The FOC with respect to $\pi$ is

Note that:

$$
\frac{d L}{d \pi}=\sum_{i} \omega_{i} \frac{d L_{i}}{d \pi}+\sum_{i} \omega_{i}\left(L_{i}-\sum_{j} \omega_{j} L_{j}\right)\left(\frac{d L_{i}}{d \pi}-\sum_{j} w_{j} \frac{d L_{j}}{d \pi}\right)=0
$$

$$
\frac{d L_{i}}{d \pi}=\pi-\alpha \lambda\left(u^{*}-\bar{u}+\alpha \pi^{e}-\alpha \pi+\alpha \varepsilon_{a}\right)+v_{i}\left(1+\alpha^{2} \lambda\right)
$$




$$
\begin{aligned}
& \frac{d L_{i}}{d \pi}-\sum_{j} w_{j} \frac{d L_{j}}{d \pi}=\left(1+\alpha^{2} \lambda\right)\left(v_{i}-\sum_{j} \omega_{j} v_{j}\right) \\
& L_{i}-\sum_{j} \omega_{j} L_{j}= \frac{1}{2}\left(1+\alpha^{2} \lambda\right)\left(v_{i}^{2}-\sum_{j} \omega_{j} v_{j}^{2}\right) \\
&+\left(\pi-\alpha \lambda\left(u^{*}-\bar{u}+\alpha \pi^{e}-\alpha \pi+\alpha \varepsilon_{a}\right)\right)\left(v_{i}-\sum_{j} \omega_{j} v_{j}\right)
\end{aligned}
$$

So plugging these into the FOC yields

$$
\begin{aligned}
\pi\left(1+\alpha^{2} \lambda\right)-\alpha & \lambda\left(u^{*}-\bar{u}+\alpha \pi^{e}+\alpha \varepsilon_{a}\right)+\left(1+\alpha^{2} \lambda\right) \sum_{i} \omega_{i} v_{i} \\
& +\frac{\kappa}{2}\left(1+\alpha^{2} \lambda\right)^{2} \sum_{i} \omega_{i}\left(v_{i}^{2}-\sum_{j} \omega_{j} v_{j}^{2}\right)\left(v_{i}-\sum_{j} \omega_{j} v_{j}\right) \\
& +\kappa\left(1+\alpha^{2} \lambda\right)\left(\pi\left(1+\alpha^{2} \lambda\right)-\alpha \lambda\left(u^{*}-\bar{u}+\alpha \pi^{e}+\alpha \varepsilon_{a}\right)\right) \sum_{i} \omega_{i}\left(v_{i}-\sum_{j} \omega_{j} v_{j}\right)^{2}=0
\end{aligned}
$$

Note that the population-weighted cross-region variance of unemployment rates is

$$
\operatorname{var}\left(u_{i}\right) \equiv \sum_{i} \omega_{i}\left(u_{i}-\sum_{j} \omega_{j} u_{j}\right)^{2}=\alpha^{2} \sum_{i} \omega_{i}\left(v_{i}-\sum_{j} \omega_{j} v_{j}\right)^{2}=\alpha^{2} \sum_{i} \omega_{i} v_{i}^{2}-\left(\sum_{i} \omega_{i} v_{i}\right)^{2}
$$

while the population-weighted skew (not normalized by the standard deviation) is

$$
\begin{aligned}
s k\left(u_{i}\right) & \equiv \sum_{i} \omega_{i}\left(u_{i}-\sum_{j} \omega_{j} u_{j}\right)^{3}=-\alpha^{3} \sum_{i} \omega_{i}\left(v_{i}-\sum_{j} \omega_{j} v_{j}\right)^{3} \\
& =-\alpha^{3} \sum_{i} \omega_{i} v_{i}^{3}+3 \alpha^{3}\left(\sum_{i} \omega_{i} v_{i}^{2}\right)\left(\sum_{i} \omega_{i} v_{i}\right)-2 \alpha^{3}\left(\sum_{i} \omega_{i} v_{i}\right)^{3} \\
& =-\alpha^{3} \sum_{i} \omega_{i} v_{i}^{3}+\alpha^{3}\left(\sum_{i} \omega_{i} v_{i}^{2}\right)\left(\sum_{i} \omega_{i} v_{i}\right)+2 \alpha\left(\sum_{i} \omega_{i} v_{i}\right) \operatorname{var}\left(u_{i}\right)
\end{aligned}
$$

Substituting these expressions into the FOC yields

$$
\begin{aligned}
\pi\left(1+\alpha^{2} \lambda\right)-\alpha & \lambda\left(u^{*}-\bar{u}+\alpha \pi^{e}+\alpha \varepsilon_{a}\right)+\left(1+\alpha^{2} \lambda\right) \sum_{i} \omega_{i} v_{i} \\
+ & \frac{\kappa}{2 \alpha^{3}}\left(1+\alpha^{2} \lambda\right)^{2}\left(2 \alpha\left(\sum_{i} \omega_{i} v_{i}\right) \operatorname{var}\left(u_{i}\right)-\operatorname{sk}\left(u_{i}\right)\right) \\
+ & \frac{\kappa}{\alpha^{2}}\left(1+\alpha^{2} \lambda\right)\left(\pi\left(1+\alpha^{2} \lambda\right)-\alpha \lambda\left(u^{*}-\bar{u}+\alpha \pi^{e}+\alpha \varepsilon_{a}\right)\right) \operatorname{var}\left(u_{i}\right)=0
\end{aligned}
$$

Note that the optimal policy when $\kappa=0$ is given by

so the FOC can be rewritten as

$$
\pi^{o p t}=\frac{\alpha \lambda}{1+\alpha^{2} \lambda}\left(u^{*}-\bar{u}+\alpha \pi^{e}+\alpha \varepsilon_{a}\right)-\sum_{i} \omega_{i} v_{i}
$$




$$
\left(1+\alpha^{2} \lambda\right)\left(\pi-\pi^{o p t}\right)+\frac{\left(1+\alpha^{2} \lambda\right) \kappa}{\alpha^{2}}\left(\pi-\pi^{o p t}\right) \operatorname{var}\left(u_{i}\right)=\frac{\kappa}{2 \alpha^{3}}\left(1+\alpha^{2} \lambda\right)^{2} \operatorname{sk}\left(u_{i}\right)
$$

which, after rearranging, yields the equation in Proposition 2.

\section{Proof of Proposition 3:}

The first-order condition with respect to inflation is

$$
\pi-\lambda \alpha(u-\bar{u})=0
$$

where $\quad u=\sum_{i} \omega_{i} u_{i}=\sum_{i} \omega_{i}\left(u^{*}+\alpha_{i}\left(\pi^{e}-\pi+\varepsilon_{i}\right)\right)=u^{*}+\alpha\left(\pi^{e}-\pi+\widetilde{\varepsilon_{a}}\right)+\sum_{i} \omega_{i}\left(\alpha_{i}-\alpha\right) \varepsilon_{i} \quad$ and $\varepsilon_{i} \equiv \varepsilon_{a}-v_{i}$ and $\alpha \equiv \sum \omega_{i} \alpha_{i}$. Then the first-order condition can be rewritten as

$$
\pi=\frac{\alpha \lambda}{1+\alpha^{2} \lambda}\left(u^{*}-\bar{u}+\alpha \pi^{e}+\alpha \widetilde{\varepsilon_{a}}\right)+\frac{\alpha \lambda}{1+\alpha^{2} \lambda} \sum_{i} \omega_{i}\left(\alpha_{i}-\alpha\right) \varepsilon_{i} .
$$

Now given regional Phillips curves $\varepsilon_{i}=\pi-\pi^{e}+1 / \alpha_{i}\left(u_{i}-u^{*}\right)$, it follows that

$$
\sum_{i} \omega_{i}\left(\alpha_{i}-\alpha\right) \varepsilon_{i}=\sum_{i} \omega_{i}\left(1-\frac{\alpha}{\alpha_{i}}\right)\left(u_{i}-u^{*}\right)
$$

Plugging this into the first-order condition yields the equation in Proposition 3.

\section{Appendix 2: Information on Macroeconomic Shocks in Section 2.3}

- Technology shocks are identified as in Gali (1999) who uses long-run restrictions in a 2 variable VAR of labor productivity and hours. Technology shocks are identified from the restriction that only technology shocks have long run effect on productivity.

- News shocks are identified as in Beaudry and Portier (2006). We use the short-run restrictions imposed on the residuals of a bivariate $\operatorname{VAR}(4)$ which includes total factor productivity (TFP) and the S\&P500 price index. As discussed in Beaudry and Portier (2006), the short run restriction imposes that TFP does not respond to a news shock contemporaneously while the stock market does.

- Oil price shocks are taken from Hamilton (1996) who identifies oil price shocks as episodes when the current oil price exceeds the maximum oil price over the last twelve months. When this is the case, the shock is the difference between the current price and the maximum over the last twelve months, and zero otherwise. We take logs of all prices.

- Uncertainty shocks are from Bloom (2009) which uses the volatility of stock prices to measure uncertainty.

- Tax shocks are exogenous tax changes as a share of GDP, from Romer and Romer (2009) who use narrative approach to identify exogenous changes in taxes. 


\section{Appendix 3: States associated with each Fed District}

District 1: Connecticut, Maine, Massachusetts, New Hampshire, Rhode Island, and Vermont.

District 2: New York

District 3: Pennsylvania, Delaware, New Jersey.

District 4: Ohio.

District 5: Washington DC, Maryland, Virginia, North and South Carolina, West Virginia.

District 6: Alabama, Florida, Georgia, Louisiana, Mississippi, and Tennessee.

District 7: Iowa, Illinois, Indiana, Michigan, and Wisconsin.

District 8: Arkansas, Missouri, and Kentucky.

District 9: Minnesota, Montana, North and South Dakota.

District 10: Colorado, Kansas, Nebraska, Oklahoma, Wyoming, and New Mexico.

District 11: Texas.

District 12: California, Arizona, Utah, Nevada, Oregon, Washington, Idaho, Alaska, and Hawaii.

Because some states are split between Federal Reserve districts, this allocation only approximately captures the division of states across districts. 